\title{
Influence of negative- $U$ centers related carrier dynamics on donor-acceptor-pair emission in fluorescent SiC
}

\author{
Wei, Yi; Tarekegne, Abebe Tilahun; Ou, Haiyan
}

Published in:

Journal of Applied Physics

Link to article, DOI:

$10.1063 / 1.5037167$

Publication date:

2018

Document Version

Publisher's PDF, also known as Version of record

Link back to DTU Orbit

Citation (APA):

Wei, Y., Tarekegne, A. T., \& Ou, H. (2018). Influence of negative- $U$ centers related carrier dynamics on donoracceptor-pair emission in fluorescent SiC. Journal of Applied Physics, 124(5), [054901]. https://doi.org/10.1063/1.5037167

\section{General rights}

Copyright and moral rights for the publications made accessible in the public portal are retained by the authors and/or other copyright owners and it is a condition of accessing publications that users recognise and abide by the legal requirements associated with these rights.

- Users may download and print one copy of any publication from the public portal for the purpose of private study or research.

- You may not further distribute the material or use it for any profit-making activity or commercial gain

- You may freely distribute the URL identifying the publication in the public portal 


\section{Influence of negative-U centers related carrier dynamics on donor-acceptor-pair emission in fluorescent SiC}

Yi Wei, Abebe Tilahun Tarekegne, and Haiyan Ou

Citation: Journal of Applied Physics 124, 054901 (2018); doi: 10.1063/1.5037167

View online: https://doi.org/10.1063/1.5037167

View Table of Contents: http://aip.scitation.org/toc/jap/124/5

Published by the American Institute of Physics

\section{Articles you may be interested in}

Vertical leakage mechanism in GaN on Si high electron mobility transistor buffer layers

Journal of Applied Physics 124, 055702 (2018); 10.1063/1.5027680

Identification of low-energy peaks in electron emission spectroscopy of InGaN/GaN light-emitting diodes

Journal of Applied Physics 124, 055703 (2018); 10.1063/1.5030208

Donors and deep acceptors in $\beta-\mathrm{Ga}_{2} \mathrm{O}_{3}$

Applied Physics Letters 113, 062101 (2018); 10.1063/1.5034474

On the structure and photoluminescence of dislocations in silicon

Journal of Applied Physics 124, 053106 (2018); 10.1063/1.5011329

Ultrafast bulk carrier recombination transients in n-type and semi-insulating $4 \mathrm{H}-\mathrm{SiC}$ crystals

Applied Physics Letters 112, 201904 (2018); 10.1063/1.5025590

Theoretical analysis of Hall factor and hole mobility in p-type 4H-SiC considering anisotropic valence band structure

Journal of Applied Physics 123, 245704 (2018); 10.1063/1.5025776

\section{AIPP| Iopplied of Physics SPECIAL TOPICS}

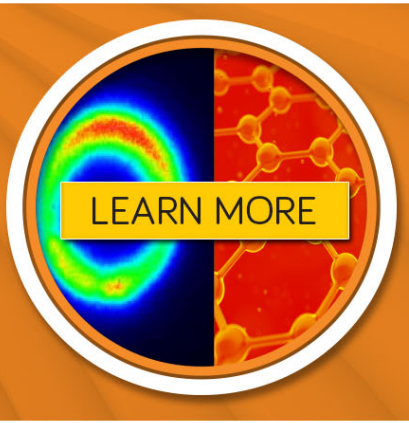




\title{
Influence of negative- $U$ centers related carrier dynamics on donor-acceptor-pair emission in fluorescent SiC
}

\author{
Yi Wei, Abebe Tilahun Tarekegne, and Haiyan $\mathrm{Ou}^{\mathrm{a})}$ \\ Department of Photonics Engineering, Technical University of Denmark, DK-2800 Kgs. Lyngby, Denmark
}

(Received 21 April 2018; accepted 11 July 2018; published online 1 August 2018)

\begin{abstract}
$E_{1} / E_{2}$ defects are the typical negative- $U$ centers in $n$-type $6 \mathrm{H}$ silicon carbide $(\mathrm{SiC})$. They are the main contributors to non-radiative recombination, which limits the carrier lifetime. In this study, two fluorescent $6 \mathrm{H}$ silicon carbide ( $\mathrm{f}-\mathrm{SiC}$ ) samples and one bulk substrate were characterized via time-resolved photoluminescence (TRPL) and static photoluminescence (PL) measurements, where all the samples were nitrogen-boron co-doped $6 \mathrm{H} n$-type. The existence of $E_{1} / E_{2}$ defects, which caused the diminution of the internal quantum efficiency (IQE) and luminescence intensity of each sample, was confirmed by applying a carrier dynamics model based on negative- $U$ centers. The carrier dynamics simulation reveals that the density of the $E_{1} / E_{2}$ defects in bulk $6 \mathrm{H} \mathrm{SiC}$ is two orders of magnitude higher than that of the f-SiC sample, causing much lower PL intensity in the bulk substrate compared to the two f-SiC samples. The IQE of the two f-SiC samples was extracted from the corresponding TRPL results, where the contrast between their IQE was further confirmed by the related PL measurement results. The slight difference in IQE between the two f-SiC samples was attributed to slightly different $E_{1} / E_{2}$ defect concentrations. On the other hand, by implementing a steady-state donor-acceptor-pair (DAP) recombination calculation, it was found that the f-SiC sample with lower IQE had a higher DAP transition probability due to the higher doping level. This prompted further optimizations in the $\mathrm{f}-\mathrm{SiC}$ crystal growth conditions in order to decrease the $E_{1} / E_{2}$ defects while maintaining the correct doping parameters. Published by AIP Publishing.

https://doi.org/10.1063/1.5037167
\end{abstract}

\section{INTRODUCTION}

Fluorescent silicon carbide (f-SiC) is a novel optoelectronic material capable of displaying strong orange-yellow light emission with a broad spectrum. ${ }^{1}$ Owing to its sufficient thickness $(>10 \mu \mathrm{m})$ with high-density $\left(>10^{18} \mathrm{~cm}^{-3}\right)$ donoracceptor-pairs (DAPs), ${ }^{1}$ f-SiC is anticipated to realize efficient wavelength conversion from the near-ultraviolet (NUV) to the visible light spectral region. The high density of DAP is achieved by the heavy nitrogen (N) and boron (B) co-doping during growth where $n$-type $\mathrm{f}-\mathrm{SiC}$ is eventually formed. $\mathrm{f}-\mathrm{SiC}$ has a number of properties amenable to future requirements for solid-state lighting. For instance, compared with yellow phosphors, f-SiC contains no rare-earth elements $^{2}$ and has no issue of degradation; hence, it is believed that ${ }^{1-5} \mathrm{f}-\mathrm{SiC}$ is a promising substitute for yellow phosphors for future white light-emitting diodes (LEDs). Besides, its high thermal conductivity makes it ideal for high power LED applications. Much progress has been made toward realizing the new type of white LEDs based on f-SiC. For instance, a prototype of white LED was proposed through f$\mathrm{SiC}$ being pumped by a gallium nitride $(\mathrm{GaN})$ based multiple-quantum-well (MQW) NUV source, ${ }^{2,4}$ where the NUV stack was grown on the f-SiC substrate. Meanwhile, efforts have also been made toward enhancing the light extraction efficiency of f-SiC by using, e.g., antireflective subwavelength conical ${ }^{6}$ and wavelength-scale nanodome structures, ${ }^{7}$ which have resulted in enhancements of $66.3 \%$ and $138 \%$, respectively. Later on, the hybrid $\mathrm{f}-\mathrm{SiC}$ structure combining

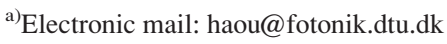

as-grown $\mathrm{f}$-SiC with the porous $\mathrm{f}-\mathrm{SiC}$ surface $\operatorname{layer}^{8}$ has achieved white light emission with a color rendering index (CRI) as high as 81.1. As the luminescence efficiency is the cornerstone of the lighting source based on $\mathrm{f}-\mathrm{SiC}$ where the emission quality is quite sensitive to the doping levels of both $n$ - and $p$-type dopants, a lot of efforts have been made toward optimizing the doping conditions. It has been found that both $\mathrm{B}$ and $\mathrm{N}$ concentrations are required to exceed $10^{18} \mathrm{~cm}^{-3}$ and the difference between those two concentrations needs to be larger than $4 \times 10^{18} \mathrm{~cm}^{-3}$ (Refs. 9 and 10) in order to induce high intensity DAP recombination.

However, the internal quantum efficiency (IQE) of typical f-SiC samples is still fairly low, indicating that a significant proportion of carriers goes through non-radiative recombination pathways. Several studies have been reported about the investigations on the non-radiative recombinations in $\mathrm{f}-\mathrm{SiC}$ through experimental approaches. It was first found that ${ }^{5}$ the centers for non-radiative recombinations are distinct from the DAP recombination centers in $\mathrm{f}-\mathrm{SiC}$. Later on, it was suggested that ${ }^{11}$ the competing recombination regime against DAP recombination in $\mathrm{f}-\mathrm{SiC}$ might be related to $E_{1} /$ $E_{2}$ centers. Likewise, it was also believed that ${ }^{12}$ the nitrogen doping could facilitate the formation of the vacancy related defects, e.g., the $E_{1} / E_{2}$ centers which contribute to nonradiative recombinations. In fact, the $E_{1} / E_{2}$ centers have been identified as the dominating intrinsic point defects in $n$ type $6 \mathrm{H} \mathrm{SiC}^{13-15}$ and found to originate from the same point defects as the $Z_{1} / Z_{2}$ centers in $4 \mathrm{H} \mathrm{SiC}{ }^{16,17}$ It is widely accepted that the $E_{1} / E_{2}$ centers are related to the carbon vacancy $\left(V_{C}\right)$ in $6 \mathrm{H} \mathrm{SiC}^{13,15,18}$ 
By characterizing an $n$-type $6 \mathrm{H}$ SiC-based Schottky diode via deep level transient spectroscopy (DLTS), it was discovered that ${ }^{19} E_{1} / E_{2}$ centers were associated with two acceptor-like levels and might be important for electron-hole $\left(e^{-}-h^{+}\right)$pair recombination. Soon afterwards, the DLTS peaks of $E_{1} / E_{2}$ centers were found ${ }^{20}$ to correlate with a twostage ionization process from either the $E_{1}^{-}$or $E_{2}^{-}$acceptor levels, where the charge states of either center was transferred in the sequence $E_{1 / 2}^{-} \rightarrow E_{1 / 2}^{0}+e^{-} \rightarrow E_{1 / 2}^{+}+2 e^{-}$ ( $E_{1 / 2}$ represents the $E_{1}$ or $E_{2}$ center) associated with single $e^{-}$emission within each stage. This two-stage ionization indicated that the binding energies of $E_{1} / E_{2}$ centers were strengthened when capturing the second $e^{-}$, suggesting the existence of the so-called negative- $U$ system. ${ }^{21}$ Assuming that two $e^{-}$are bound to a lattice-vacancy in a group-IV semiconductor, ${ }^{22}$ one $e^{-}$should normally be bound more tightly to the defect if the other $e^{-}$has been removed. However, if the ionization of the $e^{-}$which was captured by the defect later requires larger energy, the related defect center is said to possess a negative- $U$ property. As these two $e^{-}$are being paired in the dangling bonds of a defect and meanwhile being coupled with a large lattice relaxation, ${ }^{23}$ it could give rise to considerable energy gain for the $e^{-}$pairs. The cause of this negative- $U$ behavior, where two $e^{-}$appear to have a net attractive interaction macroscopically, could be explained by the fact that the energy gain of $e^{-}$is able to break the Coulomb barrier between the two $e^{-}$. A theoretical framework $^{24,25}$ via first-principles calculations has been developed to study the negative- $U$ behavior of the carbon vacancy in SiC. It was found that the generation of a carbon vacancy in $\mathrm{SiC}$ is accompanied by significant Jahn-Teller distortion, where the aforementioned energy gain of an $e^{-}$is actually introduced by the Jahn-Teller distortion in the case of neutral carbon vacancy with a symmetry lowering.

Although $E_{1} / E_{2}$ centers have been widely observed by applying DLTS on as-grown and irradiated $6 \mathrm{H} \mathrm{SiC} \mathrm{sam-}$ ples, ${ }^{13-15,17-19,26,27}$ so far, the DLTS measurement report is not available for $\mathrm{f}-\mathrm{SiC}$ samples. It is still difficult to fabricate a metal-insulator-semiconductor (MIS) structure Schottky diode with low leakage current based on $\mathrm{f}$-SiC for DLTS measurements because of the very high free carrier density at thermal equilibrium. ${ }^{28,29}$ Alternatively, in order to study how $E_{1} / E_{2}$ centers affect the IQE of $\mathrm{f}-\mathrm{SiC}$ which is mainly dependent on the radiative DAP recombination, it is preferable to apply time-resolved photoluminescence (TRPL) and static photoluminescence (PL) measurements on $\mathrm{f}-\mathrm{SiC}$, since they are nondestructive methods and do not require timeintensive contact preparation.

In this work, we quantitatively demonstrate how the negative- $U$ centers $\left(E_{1} / E_{2}\right.$ defects) affect recombination in $\mathrm{f}-\mathrm{SiC}$ in parallel with the DAP recombination process. The rapid luminescence decay in $\mathrm{f}-\mathrm{SiC}$ is successfully explained by applying a negative- $U$ center related carrier dynamics model. A steady-state DAP recombination model is also implemented to reveal how the DAP related process could be affected by the presence of negative- $U$ centers. Moreover, we investigated the carrier dynamics of N-B co-doped $n$-type $6 \mathrm{H}$ bulk $\mathrm{SiC}$ to compare with $\mathrm{f}-\mathrm{SiC}$ and showed that an additional trapping center is found other than $E_{1} / E_{2}$ defects in the bulk material.

\section{EXPERIMENTAL}

TRPL measurements of $6 \mathrm{H} \mathrm{SiC}$ were previously done by others to extract information about different recombination channels which could be either radiative or non-radiative. ${ }^{30,31}$ Here, we believe that two recombination channels corresponding to negative- $U$ centers assisted recombination and DAP recombination are present. By applying the multi-phase exponential decay fitting to the measured TRPL curves, two parameters of each recombination channel can be obtained: the recombination lifetime (time constant) and the amplitude which indicates the relative "load capacity" of the nonequilibrium carriers. On the other hand, the static PL characterizations were applied in order to get the relative efficiency of the steady-state DAP recombination. Based on the parameters extracted from each recombination channel, the reason for the different static PL intensities measured for different samples were interpreted quantitatively. The related computational methods will be introduced in Sec. III.

The specifications of the three samples employed in this research, labelled as EP-A, EP-B ("EP" for the A-SiC epilayer), and $\mathrm{BK}$ ("BK" represents the $6 \mathrm{H}$ bulk $\mathrm{SiC}$ ), are summarized in Table I. The epilayers of the $\mathrm{f}-\mathrm{SiC}$ samples were grown on the (0001) plane with low off-axis (orientation: $\left.\langle 11 \overline{2} 0\rangle \pm 1.4^{\circ}\right)$ and $250 \mu \mathrm{m}$ thick $6 \mathrm{H} \quad \mathrm{SiC}$ substrates (SiCrystal $\mathrm{GmbH}$ ) using the fast sublimation growth process $(\text { FSGP) })^{32,33}$ at $1725^{\circ} \mathrm{C}$. A commercial (TanKeBlue Ltd.) $6 \mathrm{H}$ bulk $\mathrm{SiC}$ sample with top and bottom sides (orientation: $\left.\langle 0001\rangle \pm 0.5^{\circ}\right)$ polished using chemical mechanical polishing (CMP) was applied as the reference.

Both TRPL and PL measurements were performed at room temperature (RT). Both the input laser beam and the emission signal to be detected were fiber-coupled to a $50 \times$ microscope lens in a front excitation/front detection

TABLE I. Essential parameters of each $6 \mathrm{H} \mathrm{SiC} \mathrm{sample.}$

\begin{tabular}{lccc}
\hline \hline Sample $\Rightarrow$ & EP-A & EP-B & BK \\
\hline$d(\mu \mathrm{m})^{\mathrm{a}}$ & \multicolumn{2}{c}{$45+250$} & 325 \\
Dim. $\left(\mathrm{cm}^{2}\right)$ & $0.8 \times 0.5$ & $1.2 \times 1.2$ & $0.5 \times 0.5$ \\
$N_{d}\left(\times 10^{18} \mathrm{~cm}^{-3}\right)^{\mathrm{b}}$ & 9.0 & 9.2 & 5.4 \\
$N_{a}\left(\times 10^{18} \mathrm{~cm}^{-3}\right)^{\mathrm{b}}$ & 4.4 & 5.2 & 0.95 \\
$E_{g}(\mathrm{meV})^{\mathrm{c}}$ & 2984 & 2982 & 2998 \\
$E_{F}(\mathrm{meV})^{\mathrm{c}}$ & 2885 & 2879 & 2903 \\
$n_{0}\left(\times 10^{18} \mathrm{~cm}^{-3}\right)^{\mathrm{c}}$ & 1.90 & 1.69 & 2.34 \\
$N_{u}\left(\times 10^{12} \mathrm{~cm}^{-3}\right)^{\mathrm{d}}$ & 2.08 & 3.50 & 172 \\
$Z_{\mathrm{eff}}(\mu \mathrm{m})^{\mathrm{e}}$ & & 17.33 & \\
$g\left(\mathrm{~cm}^{-3}\right)^{\mathrm{e}}$ & & $4.57 \times 10^{11}$ & \\
\hline \hline
\end{tabular}

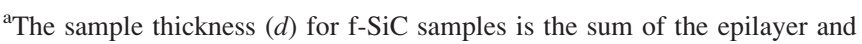
the substrate.

${ }^{\mathrm{b}}$ The dopant concentrations (Nitrogen: $N_{d} \mid$ Boron: $N_{a}$ ) were characterized by secondary-ion mass spectroscopy (SIMS).

${ }^{\mathrm{c}}$ The calculation of the bandgap $\left(E_{g}\right)$, the Fermi level $\left(E_{F}\right)$, and the carrier density at thermal equilibrium $\left(n_{0}\right)$ is derived from Refs. 36 and 72-75.

${ }^{\mathrm{d}}$ The determination of the total density of the negative- $U$ center $\left(N_{u}\right)$ of each sample can be found in Sec. III A.

${ }^{\mathrm{e}}$ The effective penetration depth $\left(Z_{\text {eff }}\right)$ and the injection level $(g)$ were determined by the methods mentioned in Sec. II. 
configuration. For either TRPL or PL measurement, different numbers of spots were characterized on different samples (BK: two/EP-A: three/EP-B: nine) considering the dimension of each sample shown in Table I.

The key components of the experimental setup of the TRPL system were from PicoQuant GmbH. Short laser pulses were generated by a picosecond diode laser (LDH828, $\lambda=375 \mathrm{~nm}, 44 \mathrm{ps}$ pulse width with a pulse repetition rate up to $80 \mathrm{MHz}$ ). The laser beam was focused onto the sample via the $50 \times$ lens with a numerical aperture (NA) of 0.8 , where the diameter (D) of the laser spot on the sample was measured to be approximately $0.22 \mathrm{~mm}$. After that, the emitted photons from the sample were filtered by a long-pass $405 \mathrm{~nm}$ filter and then detected by a photon-multiplier tube (PMA Hybrid). Finally, the photoluminescence decay was recorded by a time correlated single photon counting system (abbrev. TCSPC, TimeHarp 260 NANO).

The criterion for choosing the time span for each measurement was to record the decay profile as complete as possible while preventing interference from the background noise [typically $80-120$ counts per second (cps)]. $20 \mu \mathrm{s} / 2 \mathrm{~ms}$ ranges were chosen for sample BK/sample EP-A(B), respectively. A $500 \mathrm{~Hz}$ repetition rate laser pulse was chosen for the measurement on the two f-SiC samples with a resolution of $80 \mathrm{~ns}$ and an integration time of $1 \mathrm{~h}$. Accordingly, the $50 \mathrm{kHz}$ laser pulse with a beam power of $\sim 91.35 \mathrm{nW}$ was chosen for the measurement of the bulk sample with a ps resolution of 800 and an integration time of $30 \mathrm{~min}$ for the more rapid decay. In order to calculate the injection level $g\left(\mathrm{~cm}^{-3}\right)$ which is essential for our modelling, the pulsed beam power was measured by an optical power meter (Thorlabs PM100D). Here, we believed that the energy of a single pulse is independent of the pulse repetition rate; hence, we measured the beam power at a repetition rate of $500 \mathrm{kHz}$ to eliminate the interference from noise and obtained a beam power of $\sim 920 \mathrm{nW}$. We implemented this value to the calculations of the injection levels for all three samples. Then, we calculated the photon density $I_{0}\left(\mathrm{~cm}^{-2}\right)$ of the laser spot. The average injection level was determined by assuming an effective depth ${ }^{34} Z_{\text {eff }}=\alpha^{-1} \ln \left[2 /\left(1+e^{-\alpha d}\right)\right]$, where $\alpha\left(\mathrm{cm}^{-1}\right)$ is the absorption coefficient of $6 \mathrm{H} \mathrm{SiC}$ and $d$ is the layer thickness of the sample. Here, the absorption coefficient of $6 \mathrm{H} \mathrm{SiC}$ with polarization of the laser source oriented perpendicular to the $c$-axis $(\mathbf{E} \perp \mathbf{c})$ at $375 \mathrm{~nm}$ (Ref. 35) is about $400 \mathrm{~cm}^{-1}$. Then, the injection level, which is dependent on $Z_{\text {eff }}$, can be given by $g=\alpha \times I_{0} \times e^{-\alpha Z_{\text {eff }}}$. $Z_{\text {eff }}$ and the corresponding $g$ were calculated to be almost independent of sample thickness $d$ and fixed at $17.33 \mu \mathrm{m} \mid 4.57 \times 10^{11} \mathrm{~cm}^{-3}$, respectively, for all three samples.

For PL measurements, the same pulsed laser source was applied where the pulse repetition rate was set to $500 \mathrm{kHz}$ with a beam power of $\sim 920 \mathrm{nW}$. This was to make sure that the PL intensities were measured under the same condition as the TRPL, where the injection level per pulse for PL measurements was set to be identical to that of the TRPL measurements. An optical spectrometer (CAS 140B, Instrument Systems GmbH) was implemented with the integration time set to $5 \mathrm{~s}$ for all $\mathrm{PL}$ measurements. The emitting photons from the frontside of the sample were filtered by a long-pass filter $\left(\lambda_{\text {cutoff }}=420 \mathrm{~nm}\right)$.

\section{COMPUTATIONAL METHODS}

In order to understand why the PL intensities of the three $6 \mathrm{H} \mathrm{SiC}$ samples differ, the competitive relation between the negative- $U$ centers assisted recombination and the DAP recombination needs to be analyzed numerically. This could be achieved by combining the negative- $U$ center related carrier dynamics and the steady-state DAP recombination calculation together, where the parameters of the corresponding recombination channels are applied for the inputs of each in the model.

The overall framework of the negative- $U$ center related carrier dynamics simulation was based on the method used in Ref. 34. The authors discussed the carrier dynamics simulation of the negative- $U$ centers $Z_{1} / Z_{2}$ in $4 \mathrm{H} \mathrm{SiC}$, where the $Z_{1}$ and $Z_{2}$ centers were combined together as a single negative- $U$ center in the simulation. Since the equivalence between the $Z_{1} / Z_{2}$ centers in $n$-type $4 \mathrm{H} \mathrm{SiC}$ and the $E_{1} / E_{2}$ centers in $n$-type $6 \mathrm{H} \mathrm{SiC}$ has been confirmed by previous research, ${ }^{15,37}$ the methodology is also applicable for modelling the $E_{1} / E_{2}$ center related carrier dynamics in $6 \mathrm{H} \mathrm{SiC}$. Nevertheless, substantial changes have been made in this calculation, e.g., the carrier dynamics related to the three types of negative- $U$ centers (introduced in Sec. III A) in $6 \mathrm{H} \mathrm{SiC}$ were simulated separately. In addition, the influence of the heavy boron doping on the carrier dynamics was also taken into consideration. The details about the carrier dynamics simulation in $6 \mathrm{H} \mathrm{SiC}$ will be further illustrated in Sec. III A.

The approach for the calculation of the DAP recombination lifetime $\left(\tau_{\text {dap }}\right)$ was adopted from Ref. 38, where the authors describe a steady-state model for single DAP recombination in semiconductors. The model was applied for each DAP recombination channel in $6 \mathrm{H} \mathrm{SiC}$ where three donor levels and one acceptor level were included. The DAP transition probability $W\left(r_{\text {dap }}\right)$ is the crucial parameter for calculating $\tau_{\text {dap. }}$. In this work, we quantitatively demonstrate how the mean DAP separation distance $r_{\text {dap }}$ influences $W\left(r_{\text {dap }}\right)$ and how $W\left(r_{\text {dap }}\right)$ further affects $\tau_{\text {dap }}$. In addition, the estimations for the capture probabilities of each donor and acceptor are discussed. The details about the calculation of the DAP recombination lifetime in $6 \mathrm{H} \mathrm{SiC}$ will be further illustrated in Sec. III B.

Suttrop et al..$^{39}$ observed yellow luminescence with $\lambda_{\text {peak }}$ $=580 \mathrm{~nm}$ from the nitrogen-boron co-doped $6 \mathrm{H} \mathrm{SiC}$ epilayer, where they attributed this luminescence to the phonon replica of the DAP recombination related to the boroninduced deep center ( $D$-center) located at $0.58 \mathrm{eV}$ above the valence band. In our experiment, the orange-yellow emissions were observed in the three samples with $\lambda_{\text {peak }}$ around $580 \mathrm{~nm}$. Hence, in either the negative- $U$ center related carrier dynamics simulation or the $\tau_{\text {dap }}$ calculation, the $D$-center was the only acceptor level in $6 \mathrm{H} \mathrm{SiC}$ taken into consideration. The general parameters of nitrogen/boron co-doped $n$ type $6 \mathrm{H} \mathrm{SiC}$ applied in this work are listed in Table II.

\section{A. Carrier dynamics related to negative- $U$ centers}

Based on the previous results ${ }^{19,20}$ about the characterization of $E_{1} / E_{2}$ centers in $6 \mathrm{H} \mathrm{SiC}$ via the DLTS technique, the more recent findings by Koizumi et al. ${ }^{42}$ have revealed that the $E_{2}$ center could be further separated into two centers $E_{2 L}$ and $E_{2 H}$. The subscripts " $L$ " and " $H$ " indicate that the DLTS 
TABLE II. General characteristics of the nitrogen/boron co-doped $n$-type $6 \mathrm{H} \mathrm{SiC.}$

\begin{tabular}{|c|c|c|c|}
\hline Parameter & Symbol & Value & References \\
\hline$e^{-}$effective mass & $m_{e}^{*}$ & $0.71 m_{0}{ }^{\mathrm{a}}$ & 40 \\
\hline$h^{+}$effective mass & $m_{h}^{*}$ & $0.90 m_{0}{ }^{\mathrm{a}}$ & 40 \\
\hline \multicolumn{4}{|l|}{ Binding energy of } \\
\hline Donor level (cubic site $c_{1}$ ) & $\Delta E_{c 1}$ & $137.6 \mathrm{meV}$ & 41 \\
\hline Donor level (cubic site $c_{2}$ ) & $\Delta E_{c 2}$ & $142.4 \mathrm{meV}$ & 41 \\
\hline Donor level (hexagonal site $h$ ) & $\Delta E_{h}$ & $81 \mathrm{meV}$ & 41 \\
\hline Acceptor level ( $D$-center) & $\Delta E_{D}$ & $580 \mathrm{meV}$ & 39 \\
\hline \multicolumn{4}{|c|}{ Activation energy of the charge state: } \\
\hline$E_{1}^{-}$ & $\Delta E_{1}^{0 /-}$ & $390 \mathrm{meV}$ & 42 \\
\hline$E_{2 L}^{-}$ & $\Delta E_{2 L}^{0 /-}$ & $440 \mathrm{meV}$ & 42 \\
\hline$E_{2 H}^{-}$ & $\Delta E_{2 H}^{0 /-}$ & $430 \mathrm{meV}$ & 42 \\
\hline$E_{1}^{0}$ & $\Delta E_{1}^{+1 / 0}$ & $260 \mathrm{meV}$ & 42 \\
\hline$E_{2 L}^{0}$ & $\Delta E_{2 L}^{+/ 0}$ & $140 \mathrm{meV}$ & 42 \\
\hline$E_{2 H}^{0}$ & $\Delta E_{2 H}^{+/ 0}$ & $180 \mathrm{meV}$ & 42 \\
\hline \multicolumn{4}{|l|}{ Thermal barrier of: } \\
\hline$E_{1}^{0}+e^{-} \rightarrow E_{1}^{-}$transition & $\varepsilon_{b 1}$ & $48 \mathrm{meV}$ & 20 \\
\hline$E_{2}^{0}+e^{-} \rightarrow E_{2}^{-}$transition & $\varepsilon_{b 2}$ & $70 \mathrm{meV}$ & 20 \\
\hline $\begin{array}{l}e^{-} \text {capture cross section of: } \\
E_{1}^{0}+e^{-} \rightarrow E_{1}^{-} \text {transition }\end{array}$ & $\sigma_{1, e}^{0 /-\mathrm{b}}$ & $3 \times 10^{-15}$ & 20 and 42 \\
\hline & & $\times \exp \left(-\varepsilon_{b 1} /\left(k_{b} T\right)\right) \mathrm{cm}^{-2}$ & \\
\hline$E_{1}^{+}+e^{-} \rightarrow E_{1}^{0}$ transition & $\sigma_{1, e}^{+/ 0}$ & $2 \times 10^{-15} \mathrm{~cm}^{-2}$ & 42 \\
\hline$E_{2 L}^{0}+e^{-} \rightarrow E_{2 L}^{-}$transition & $\sigma_{2 L, e}^{0 /-\mathrm{b}}$ & $\begin{array}{c}6 \times 10^{-15} \\
\times \exp \left(-\varepsilon_{b 2} /\left(k_{b} T\right)\right) \mathrm{cm}^{-2}\end{array}$ & 20 and 42 \\
\hline$E_{2 L}^{+}+e^{-} \rightarrow E_{2 L}^{0}$ transition & $\sigma_{2 L, e}^{+/ 0}$ & $5 \times 10^{-16} \mathrm{~cm}^{-2}$ & 42 \\
\hline$E_{2 H}^{0}+e^{-} \rightarrow E_{2 H}^{-}$transition & $\sigma_{2 H, e}^{0 /-\mathrm{b}}$ & $\begin{array}{c}5 \times 10^{-15} \\
\times \exp \left(-\varepsilon_{b 2} /\left(k_{b} T\right)\right) \mathrm{cm}^{-2}\end{array}$ & 20 and 42 \\
\hline$E_{2 H}^{+}+e^{-} \rightarrow E_{2 H}^{0}$ transition & $\sigma_{2 H, e}^{+/ 0}$ & $7 \times 10^{-16} \mathrm{~cm}^{-2}$ & 42 \\
\hline
\end{tabular}

${ }^{\mathrm{a}} m_{0}$ refers to the free electron mass.

${ }^{\mathrm{b}} k_{b}$ refers to the Boltzmann constant.

peak of $E_{2 L}$ emerged at a lower emission rate, whereas the DLTS peak of $E_{2 H}$ emerged at a higher emission rate at certain temperatures. All three negative- $U$ centers are classified as carbon vacancy-related centers ${ }^{15}$ where $E_{1}$ defects are located at the hexagonal sites while $E_{2 L}$ and $E_{2 H}$ defects are located at the cubic sites ${ }^{13}$ in $6 \mathrm{H} \mathrm{SiC}$. In this investigation, the negative- $U$ center related carrier dynamics is based on the above-mentioned three non-equivalent defect centers.

The schematic band diagram of the non-equilibrium carrier capture process related to the negative- $U$ centers in $6 \mathrm{H}$ $\mathrm{SiC}$ is shown in Fig. 1. At RT, the $E_{i}^{-}$state acts as the ground state, where the subscript " $i$ " $(i \Rightarrow 1,2 L$, and $2 H)$ designates the component of the negative- $U$ system. This means that after the transient interaction between the injected nonequilibrium carriers and the sample material, all the excited charge states $E_{i}^{0}$ and $E_{i}^{+}$would return ideally back to the $E_{i}^{-}$ state. Note that the carrier emission from each charge state is negligible at $\mathrm{RT}^{34}$ due to very large activation energies; therefore, only the carriers' capture was considered in this simulation. Since all three samples have fairly high densities of the boron dopant $\left(>10^{17} \mathrm{~cm}^{-3}\right)$, the influence of the acceptor level ( $D$-center) on the carrier dynamics cannot be negligible, where all the non-equilibrium $h^{+}$occupy the acceptor level and almost impossible to be ionized into the valence band due to the large ionization energy. ${ }^{9}$ Therefore, the negative- $U$ center related $h^{+}$capture is believed to come from the $D$-center rather than the valence band in this

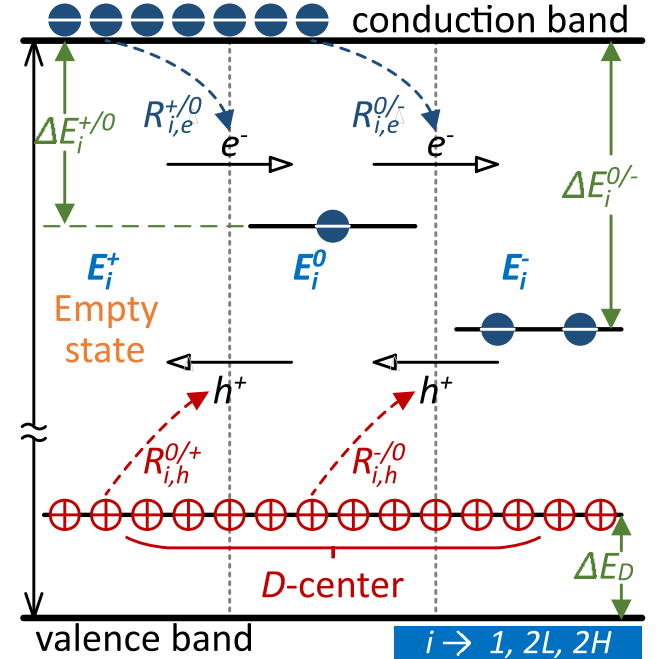

FIG. 1. A schematic band diagram of the capture process of non-equilibrium carriers via the negative- $U$ center in $6 \mathrm{H} \mathrm{SiC}$ at $\mathrm{RT}$. The subscript " $i$ " suggests the component of the negative- $U$ system: $E_{1}, E_{2 L}$, or $E_{2 H}$, each of which consists of three charge states $\left(E_{i}^{+} / E_{i}^{0} / E_{i}^{-}\right)$separated by the gray dashed lines. The capture of $e^{-}$from the conduction band or $h^{+}$from the $D$ center, which is marked by the dashed arrow, is involved in the transitions of either $E_{i}^{+} \rightleftharpoons E_{i}^{0}$ or $E_{i}^{0} \rightleftharpoons E_{i}^{-}$which are labelled with the open arrows. The activation energy of the shallow-donor-like $E^{0}$ state or the acceptor-like $E^{-}$ state is indicated by $\Delta E_{i}^{+/ 0}$ or $\Delta E_{i}^{0 /-}$, respectively, whereas the binding energy of the $D$-center is indicated by $\Delta E_{D}$.

condition. The $e^{-}$capture involved in the transition from the empty state $\left(E_{i}^{+}\right)$to the intermediate state $\left(E_{i}^{0}\right)$ is considered as a fast cascaded capturing process, ${ }^{43,44}$ while the transition from the $E_{i}^{0}$ to the $E_{i}^{-}$involving the $e^{-}$capture is considered as the slow multiphonon process ${ }^{20}$ in which the transition energy for $e^{-}$capture must be corrected with the thermal barrier. The corresponding thermal barrier for defects on hexagonal $\left(E_{1}\right)$ and cubic $\left(E_{2}\right)$ sites and the corrected $\sigma_{i, e}^{0 /-}$ for three centers are given in Table II.

It was believed that ${ }^{19}$ the capture rate of $h^{+}$should be in the same order or higher than that of the $e^{-}$for one negative$U$ center. Later on, a more specific relation where $\sigma_{i, h}^{-/ 0}$ $\approx \sigma_{i, h}^{0 /+} \approx(5 \sim 10) \times \sigma_{i, e}^{+/ 0} \gg \sigma_{i, e}^{0 /-}$ was reported. ${ }^{34}$ By fixing the value of $\sigma_{i, h}^{-/ 0}\left(\sigma_{i, h}^{0 /+}\right)$, the density of the negative- $U$ center can be estimated once the negative- $U$ center related minority carrier lifetimes $\tau_{u, i}$ at a low injection level are measured. ${ }^{45}$ Here, we assume $\sigma_{i, h}^{-/ 0}, \sigma_{i, h}^{0 /+}=\sigma_{i, h}$, and the expression of the density of each negative- $U$ center $N_{u, i}$ in $6 \mathrm{H} \mathrm{SiC}$ is shown in Eq. (1), where $\left\langle\nu_{t h, h}\right\rangle$ represents the mean thermal velocity of $h^{+}$(see Appendix A). Hereon, we assumed the relation $\sigma_{i, h}^{-/ 0}=\sigma_{i, h}^{0 /+}=5 \times \sigma_{i, e}^{+/ 0}$ in the carrier dynamics simulation for simplicity. ${ }^{46}$

The general conditions of negative- $U$ center related carrier dynamics are formulated in Appendix A. In particular, for the case of low injection level plus high carrier density in the three $6 \mathrm{H} \mathrm{SiC}$ samples (see Table I), one can suggest that $n_{0} \gg \delta n_{i}(t), p_{0} \ll \delta p_{i}(t)$, and $\delta p_{i}(t) \gg p_{i}^{0 /+}, p_{i}^{-/ 0}$. By further applying Eqs. (A2) and (A3) into Eq. (A1), the carrier capture rates can be rewritten in an analytical form as shown below 


$$
\begin{gathered}
N_{u, i}=\frac{1}{\sigma_{i, h}\left\langle\nu_{t h, h}\right\rangle \tau_{u, i}}, \\
R_{i, e}^{0 /-}(t)=\sigma_{i, e}^{0 /-}\left\langle\nu_{t h, e}\right\rangle\left\{n_{0}\left[\delta p_{i}(t)-\delta n_{i}(t)-2 \delta N_{i}^{-}(t)\right]\right. \\
\left.-n_{i}^{0 /-}\left[N_{u, i}+\delta N_{i}^{-}(t)\right]\right\}, \\
R_{i, e}^{+/ 0}(t)=\sigma_{i, e}^{+/ 0}\left\langle\nu_{t h, e}\right\rangle\left\{\left(n_{0}+n_{i}^{+/ 0}\right)\left[\delta n_{i}(t)-\delta p_{i}(t)\right]\right. \\
\left.+\left(n_{0}+2 n_{i}^{+/ 0}\right) \delta N_{i}^{-}(t)\right\}, \\
R_{i, h}^{-/ 0}(t)=\sigma_{i, h}^{-/ 0}\left\langle\nu_{t h, h}\right\rangle\left\{\delta p_{i}(t)\left[N_{u, i}+\delta N_{i}^{-}(t)\right]\right\}, \\
R_{i, h}^{0 /+}(t)=\sigma_{i, h}^{0 /+}\left\langle\nu_{t h, h}\right\rangle\left\{\delta p_{i}(t)\right. \\
\left.\times\left[\delta p_{i}(t)-\delta n_{i}(t)-2 \delta N_{i}^{-}(t)\right]\right\} .
\end{gathered}
$$

Then, we rewrote Eq. (11) in Ref. 34 in the timedependent form shown in Eq. (3). The formulation of the negative- $U$ center related carrier dynamics was built by combining Eqs. (2), (A2), and (A3)

$$
\begin{gathered}
\frac{\mathrm{d} \delta n_{i}(t)}{\mathrm{d} t}=-\left[R_{i, e}^{0 /-}(t)+R_{i, e}^{+/ 0}(t)\right], \\
\frac{\mathrm{d} \delta p_{i}(t)}{\mathrm{d} t}=-\left[R_{i, h}^{-/ 0}(t)+R_{i, h}^{0 /+}(t)\right], \\
\frac{\mathrm{d} \delta N_{i}^{-}(t)}{\mathrm{d} t}=R_{i, e}^{0 /-}(t)-R_{i, h}^{-/ 0}(t) .
\end{gathered}
$$

In actual experimental conditions, both $E_{1} / E_{2}$ related and DAP related pathways would occupy a certain proportion of the injection level $g$. Here, the portion of $g$ corresponding to the $E_{1} / E_{2}$ channels is equal to the non-equilibrium carrier density at $t=0\left(\delta n_{0}, \delta p_{0}\right)$ in the negative- $U$ center related carrier dynamics modelling. The timeresolved PL intensity $I(t)$ of $n$-type $6 \mathrm{H} \mathrm{SiC}$ at a low injection level, where $\delta n_{0}, \delta p_{0} \ll n_{0}$, is considered to be proportional to the density of non-equilibrium minority carrier $\delta p(t)$, namely, $I(t) \propto \delta p(t)$. Hence, the PL lifetime is equivalent to the lifetime of non-equilibrium $h^{+}$where $\tau_{\mathrm{PL}}(t) \cong \tau_{p}(t)$. Note that the time-dependent $h^{+}$lifetime is given by Eq. (4) where the expressions of hexagonal- and cubic-site-related $h^{+}$lifetimes were included

$$
\begin{gathered}
\tau_{p}(t)=\left[-\frac{\mathrm{d} \delta p(t)}{\mathrm{d} t} \frac{1}{\delta p(t)}\right]^{-1} \\
\tau_{p, 1}(t)=\left[-\frac{\mathrm{d} \delta p_{1}(t)}{\mathrm{d} t} \frac{1}{\delta p_{1}(t)}\right]^{-1} \\
\tau_{p, 2}(t)=\left\{-\left[\frac{\mathrm{d} \delta p_{2 L}(t)}{\mathrm{d} t}+\frac{\mathrm{d} \delta p_{2 H}(t)}{\mathrm{d} t}\right] \frac{1}{\delta p_{2 L}(t)+\delta p_{2 H}(t)}\right\}^{-1} .
\end{gathered}
$$

The model was initialized by implementing $N_{u, i}$ and $\delta n_{0}\left(\delta p_{0}\right)$, where the related values were derived from the multi-phase exponential decay fitting of the experimental TRPL curve (will be introduced in Sec. IVB). The simulations were executed using Simulink (MathWorks, Inc.) where the Bogacki-Shampine $\operatorname{method}^{47}$ was implemented with a fixed time step of 10 ps.

\section{B. Calculation of $\tau_{\text {dap }}$ by a steady-state recombination model}

In the steady-state DAP recombination model demonstrated in Ref. 38, the DAP is treated as a single defect. The charge state $S$ of this single defect, where the labelling is similar to that of Ref. 48, is designated by the number of occupied $e^{-}$as shown in Fig. 2. For example, the charge state $1^{\prime}$ represents the excited state ready for $e^{-}-h^{+}$recombination via the DAP center, in which one $e^{-}$occupies the donor level while one $h^{+}$occupies the acceptor level. The transfer of the minority carriers is crucial for DAP recombination. In Fig. 2, the solid arrows suggest the transfers of the minority carriers $\left(e^{-}\right)$in $p$-type $6 \mathrm{H} \mathrm{SiC}$ where the minority carriers recombine with the majority carriers $\left(h^{+}\right)$on the perturbed acceptor level $\left(E_{a, p}\right)$. The related charge state undergoes $S: 0 \rightarrow 1^{\prime} \rightarrow 1$ and returns to state 0 after the recombination process. The dashed arrows suggest the transfers of the minority carriers $\left(h^{+}\right)$in $n$-type $6 \mathrm{H} \mathrm{SiC}$ where the minority carriers recombine with the majority carriers $\left(e^{-}\right)$ on the perturbed donor level $\left(E_{d, p}^{j}\right)$. Note that the subscripts " $j$ " denote different lattice sites occupied by the nitrogeninduced donors [i.e., cubic $1\left(c_{1}\right)$, cubic $2\left(c_{2}\right)$, and hexagonal (h) sites]. The related charge state undergoes $S: 2 \rightarrow 1^{\prime} \rightarrow 1$ followed by a return to state 2 after the recombination process.

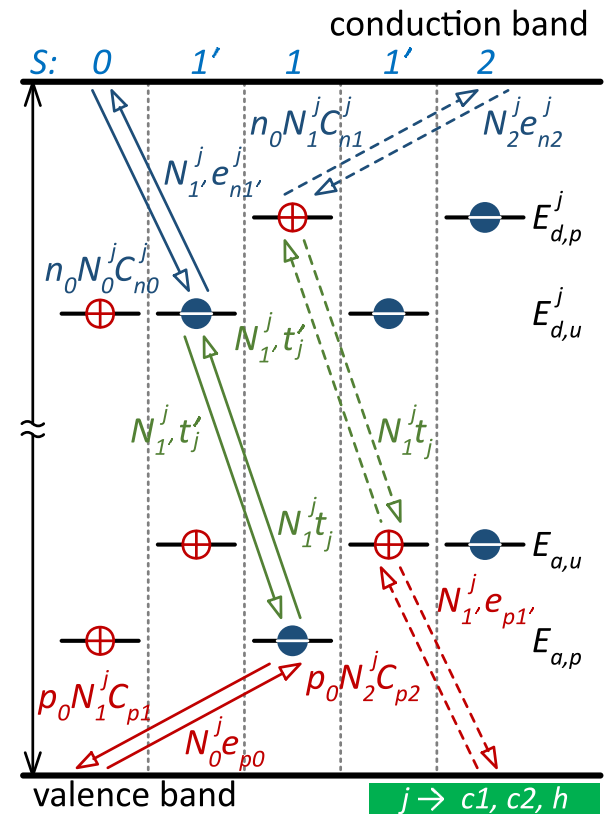

FIG. 2. A schematic band diagram of carrier generation or recombination via DAP, where $S$ represents the charge state of the pair and there are five charge states in total separated by the gray dashed lines. The perturbed donor level or acceptor level is indicated by $E_{d, p}^{j}$ or $E_{a, p}$, whereas the unperturbed donor level or acceptor level is indicated by $E_{d, u}^{j}$ or $E_{a, u}$, respectively, where the subscripts " $j$ " indicate different lattice sites occupied by the nitrogeninduced donors, namely, cubic $1\left(c_{1}\right)$, cubic $2\left(c_{2}\right)$, and hexagonal $(h)$ sites. The path consisting of solid arrows designates the recombination scheme of the strongly $p$-type $6 \mathrm{H} \mathrm{SiC}$, while the path consisting of dashed arrows designates the recombination scheme of the strongly $n$-type $6 \mathrm{H} \mathrm{SiC}$. 
The energy depths of the unperturbed donor level $\left(E_{d, u}^{j}\right)$ and the unperturbed acceptor level $\left(D\right.$-center, $\left.E_{a, u}\right)$ are indicated by $\Delta E_{j}(j=c 1, c 2, h)$ and $\Delta E_{D}$ shown in Table. II, where $c 1(c 2)$ and $h$ represent the cubic- and hexagonal-site related donor levels, respectively. The energy difference between each pair of the perturbed/unperturbed level is actually the Coulomb interaction energy $U_{E}=e^{2} /\left(4 \pi \varepsilon_{0} \varepsilon_{r} r_{\text {dap }}\right)$, where $e, \varepsilon_{0}$, and $\varepsilon_{r}$ designate the elementary charge, the vacuum permittivity, and the relative permittivity of $6 \mathrm{H} \mathrm{SiC}$, respectively. In particular, the transfers of the minority carriers involve the carrier capture/emission of the DAP at a certain charge state, e.g., $n_{0} N_{1}^{j} C_{n 1}^{j}$ indicates the $e^{-}$capture rate of the state 1 , where $N_{1}^{j} / C_{n 1}^{j}$ is the density/e capture probability of the state $l$ of the donor level $E_{j}$. Likewise, $N_{2}^{j} e_{n 2}^{j}$ indicates the $e^{-}$emission rate of state 2 where $e_{n 2}^{j}$ represents the related $h^{+}$ emission probability. The transition probability of $1^{\prime} \rightarrow 1$ or $1 \rightarrow 1^{\prime}$ related to each donor level is symbolized by $t_{j}^{\prime}$ or $t_{j}$, respectively. Since it is the $1^{\prime} \rightarrow 1$ transition that induces DAP recombination, the net steady-state recombination rate $R_{\text {dap }}$ is given by $R_{\text {dap }}=\sum_{j} N_{1^{j}}^{j} t_{j}^{\prime}-N_{1}^{j} t_{j}$. Here, $R_{\text {dap }}$ can be rewritten in the more general form ${ }^{38}$ as shown in Eq. (5), where $R_{0 \rightarrow 1^{\prime}}^{j}$ and $R_{2 \rightarrow 1^{\prime}}^{j}$ represent the net transition rate of $0 \rightarrow 1^{\prime}$ and $2 \rightarrow 1^{\prime}$, respectively. The derivation of the general conditions of the steady-state DAP recombination modelling based on Eq. (5) is described in Appendix B

$$
R_{\mathrm{dap}}=\sum_{j} R_{0 \rightarrow 1^{\prime}}^{j}+R_{2 \rightarrow 1^{\prime}}^{j}
$$

For the extrinsic $n$-type case in this research, the DAP lifetime is actually equivalent to the minority carrier lifetime, that is, $\tau_{\text {dap }} \approx \tau_{p}$. We further applied the condition of a small injection level and simplified the calculation by reconsidering the steady-state equilibrium of DAP recombination, where we let $C_{n 0}^{j}=C_{p 2}=C_{p}$ and $C_{n 1}^{j}=C_{p 1}=C_{n}^{j}$ for our condition of strong $n$-type $6 \mathrm{H} \mathrm{SiC}$. Then, we rewrote Eq. (22) in Ref. 38 for the extrinsic $n$-type case for each donorsite-dependent DAP as shown in the following equation:

$$
\begin{aligned}
\tau_{\text {dap }}^{j}= & \frac{1}{n_{0} N_{\text {eff }}^{j} W_{j}\left(r_{\text {dap }}\right)} \\
& \times \frac{\left[n_{0} p_{a, u}\left(n_{0}+n_{d, p}^{j}\right)\right] C_{n, j}^{2}+\left[p_{a, u}\left(p_{a, p}+n_{d, p}^{j}\right)\left(n_{0}+n_{d, p}^{j}\right)\right] C_{p} C_{n, j}+n_{0} W_{j}\left(r_{\text {dap }}\right)\left[\left(n_{0}+n_{d, p}^{j}\right) C_{n, j}+p_{a, p} C_{p}\right]}{n_{0} C_{n, j}^{2}+C_{p} C_{n, j}\left(n_{d, p}^{j}+p_{a, p}\right)} .
\end{aligned}
$$

The ratio between the donor level concentrations on hexagonal and cubic sites is considered ${ }^{49}$ to be identical to the ratio of the number of hexagonal and cubic sites in the crystal lattices, where $N_{h} / N_{c}=1: 2$ (subscripts " $h$ ": hexagonal and " $c$ ": cubic) for $6 \mathrm{H} \mathrm{SiC.} \mathrm{We} \mathrm{further} \mathrm{assumed} \mathrm{that} \mathrm{the} \mathrm{number} \mathrm{of}$ $c 1$ and $c 2$ sites is equal, implying the same donor level concentration related to $h, c 1$, and $c 2$ sites. Accordingly, the mean DAP recombination lifetime of the separate recombination processes is calculated by the following equation:

$$
\tau_{\text {dap }}=\frac{\sum_{j}\left(\tau_{\text {dap }}^{j}\right)^{2}}{\sum_{j} \tau_{\text {dap }}^{j}} .
$$

\section{RESULTS AND DISCUSSION}

The measured TRPL results of the three samples were summarized in Fig. 3. The scattered data points indicate the mean time-resolved PL intensities. For sample BK, four-phase exponential decay fitting $\left[y_{0}+\sum_{n}^{4} A_{n} \exp \left(-t / t_{n}\right)\right]$ was applied on the experimental TRPL. Accordingly, the experimental TRPL data of two $\mathrm{f}-\mathrm{SiC}$ samples were fitted with a three-phase exponential decay function $\left[y_{0}+\sum_{n}^{3} A_{n} \exp \left(-t / t_{n}\right)\right]$.

\section{A. The fastest and slowest TRPL decay channels in sample BK}

The fitting on the TRPL of sample BK suggests that there are four decay channels for non-equilibrium carriers where we obtained $t_{1}=3 \mathrm{~ns}$ and $A_{1}=56.1 \%$ for the fastest channel. One probable explanation for the carrier dynamics in this channel could be the combined effect from both Auger recombination (AR) and bimolecular recombination (BR) in the $6 \mathrm{H} \mathrm{SiC}$ substrate. ${ }^{50}$ At low injection levels $\left(g \ll n_{0}\right)$, the lifetime of either AR or BR is limited by the doping level. The lifetime of $\mathrm{AR}$ is $\tau_{\mathrm{AR}}=1 /\left(\gamma_{e} n_{0}^{2}\right)$, where $\gamma_{e}$ is the Auger recombination coefficient for $e^{-}-e^{-}-h^{+}$recombination in $n$-type semiconductors and typically $\gamma_{e} \approx(3.0 \pm 0.5)$ $\times 10^{-29} \mathrm{~cm}^{6} \mathrm{~s}^{-1}$ for $6 \mathrm{H} \mathrm{SiC}{ }^{51}$ The lifetime of BR is given by $\tau_{\mathrm{BR}}=1 /\left(\gamma_{B} n_{0}\right)$, where $\gamma_{B}$ is the bimolecular recombination coefficient which has a typical value in the range of $\times 10^{-11}$ $\sim \times 10^{-12} \mathrm{~cm}^{-3} \mathrm{~s}^{-1}$ for $4 \mathrm{H} \mathrm{SiC}{ }^{51,52}$ The lifetime of the rapid decay at the initial stage $\left(\tau_{\text {rapid }}\right)$ for the $n$-type $6 \mathrm{H} \mathrm{SiC}$ substrate follows the relation $1 / \tau_{\text {rapid }}=1 / \tau_{\mathrm{AR}}+1 / \tau_{\mathrm{BR}} .{ }^{50} \mathrm{By}$ assuming that $\gamma_{B}$ of $6 \mathrm{H} \mathrm{SiC}$ is comparable to that of $4 \mathrm{H} \mathrm{SiC}$, the estimated $\tau_{\text {rapid }}$ could be comparable to $t_{1}$, i.e., within the same order of magnitude. Hence, the origin of the fastest channel still requires further investigation.

The nature of the fourth channel in sample BK ( $t_{4}=4.801 \mu$ s and $A_{4}=1.2 \%$ ) is still unknown. We confirmed by steady state modeling that the DAP recommendation process is much slower than this time constant (see details in Appendix C). This does not mean that no DAP recombination occurs in sample BK; instead, the decay channel related to DAP recombination is believed to occupy the proportion of non-equilibrium carriers less than $A_{4}$ with a longer lifetime than $t_{4}$, where the background noise has obscured this decay channel during the TRPL measurements. Additionally, the effect of surface recombination cannot correspond to this channel either. Let us consider the fundamental 

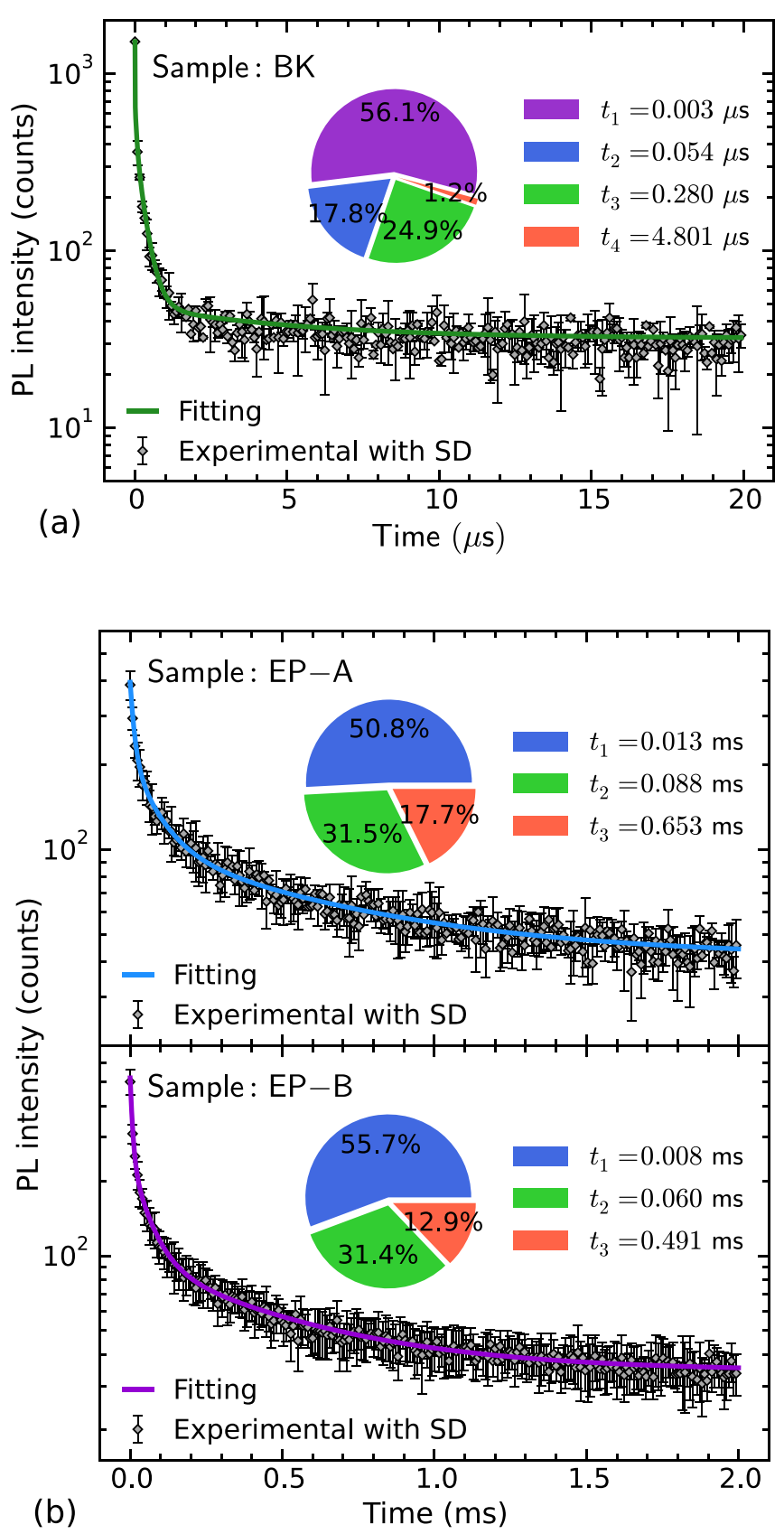

FIG. 3. TRPL decays recorded via TCSPC histograms (a) for sample BK and (b) for samples EP-A and EP-B. Each error bar indicates the standard deviation $(\mathrm{SD})$ of the measured photon count at a certain time point, whereas the solid line represents the four-phase (for sample BK) or three-phase (for samples EP-A and EP-B) exponential decay fitting. The normalized amplitudes $A_{i}$ are summarized in the pie chart, where the time constants $t_{i}$ for each $A_{i}$ are marked in the legends.

surface recombination lifetime $\left(\tau_{s}\right)^{53}$ in sample BK where $\tau_{s}=d^{2} /\left(D \pi^{2}\right)$. The diffusion constant $D=2.5 \mathrm{~cm}^{2} \mathrm{~s}^{-1}$ for hole diffusion in $6 \mathrm{H} \mathrm{SiC}$ is available from Ref. 54, from which we obtain a lower bound on $\tau_{s}^{53}$ for the sample BK of $\sim 42.8 \mu$ s which is still one order of magnitude higher than $t_{4}$.

\section{B. Negative- $U$ center related TRPL decay channels}

The second and third decay channels in sample BK were considered to be associated with the negative- $U$ center related carrier dynamics. As Ikeda et al. (Ref. 55) have experimentally demonstrated, the density ratio between the nitrogen-induced donors on hexagonal and cubic sites $\left(N_{h}: N_{c}\right)$ could be roughly treated as $1: 2$. Based on this correspondence, we believed that the amount of hexagonal-siterelated $E_{1}$ centers should be smaller than the amount of cubic-site-related $E_{2 L}$ and $E_{2 H}$ centers. Yet it may not strictly obey the 1:2 relation. Accordingly, one of those two negative- $U$ center related decay channels with larger amplitude $A_{i}$, which means taking over more non-equilibrium carriers, ought to be related to the cubic defect centers $\left(E_{2 L}\right.$ and $\left.E_{2 H}\right)$. Hence, the injection level allocated to the second channel was set to $A_{2} g$ where the density of the $E_{1}$ center was calculated using Eq. (1). Since the third channel is shared by two defect centers on cubic sites and we have assumed that these two centers have identical densities, we obtain simultaneously the defect density for both centers as $N_{u, 2 L}, N_{u, 2 H}$ $=2 /\left[\left(\sigma_{2 L, h}+\sigma_{2 H, h}\right)\left\langle\nu_{t h, h}\right\rangle t_{2}\right]$, assuming that either of the defect centers took over half of the injection level $\left(A_{3} g / 2\right)$.

The exponential decay fitting of the TRPL of both f-SiC samples (EP-A and EP-B) shows that there are three decay channels for f-SiC. By modelling the first and second channels based on the negative- $U$ center related carrier dynamics, it was found that the simulated PL decay curve agreed well with the corresponding fast decay part of each measured TRPL. Note that the allocated injection level for each channel and the densities of those three defect centers in the two samples were estimated using the same method mentioned above for sample BK. The third decay channels in both samples were believed to be related to the DAP recombination where the allocated injection level for the DAP recombination process was $A_{3} g$. Note that none of the decay channels in either f-SiC samples were attributed to surface recombination effects. The reason could be explained by the fact that the non-equilibrium carriers are hindered by the acceptorinduced space charge field at a low injection level $\left(g \ll N_{a}\right),{ }^{56-58}$ causing the diffusion coefficient $D$ to be negligible. This will result in the fundamental surface recombination lifetime ${ }^{53}$ being much longer than any extracted time constant from the TRPL measurements of both f-SiC samples.

The results of the carrier dynamics simulations are summarized in Figs. 4 and 5. In Fig. 4, for both f-SiC samples, the normalized density of the non-equilibrium minority $\left(h^{+}\right)$ carriers, which was designated by $\delta p(t) / g=\sum_{i} \delta p_{i}(t) / g$ from the simulation, agreed quite well with the negative- $U$ center related two-phase exponential decay extracted from the TRPL fitting. The simulated $\delta p(t)$ for sample BK showed a bit slower decay compared to the corresponding fitting curve, where this slight mismatch might be caused by the unknown defect centers, e.g., midgap defects in $6 \mathrm{H} \mathrm{SiC.}{ }^{59}$ We can see that the negative- $U$ center related carrier recombinations dominate the TRPL decay process before the time point indicated by the vertical dashed line [BK: $0.92 \mu \mathrm{s}$, EPA(B): $60 \mu \mathrm{s}$ ] where the decay channel with the longest time constant starts to dominate. Furthermore, the defect-related TRPL decay can be divided into two stages, where the first stage reflects the joint effect from both cubic and hexagonal centers while only the slower decay channel is highlighted at the second stage. The lifetimes of the non-equilibrium $h^{+}$for 

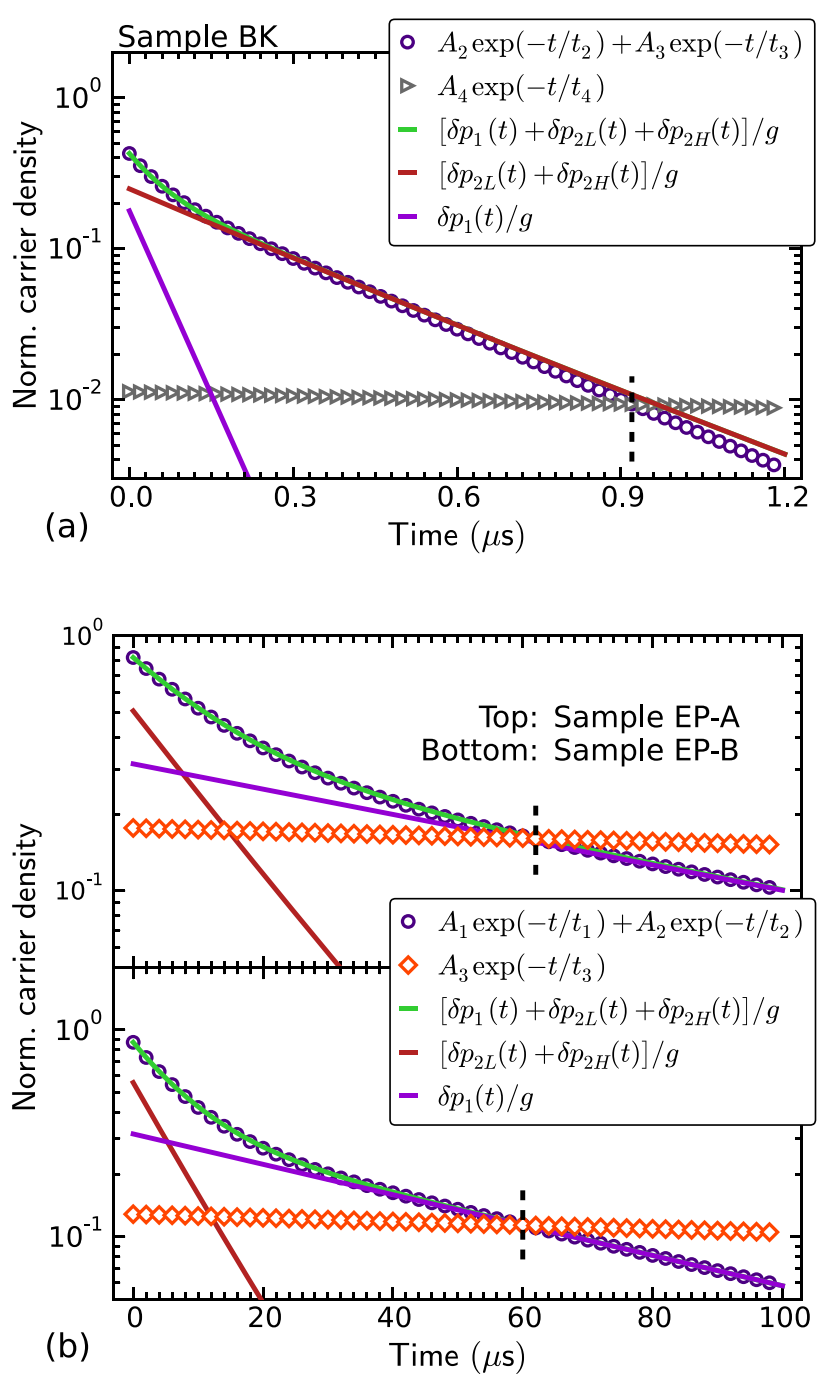

FIG. 4. Results of the negative $U$-center related carrier dynamics simulation for (a) sample BK and (b) samples EP-A and EP-B. The open circles designate the defect-related exponential decay components. The open triangles represent the decay channels with the longest time constant in the bulk $6 \mathrm{H} \mathrm{SiC}$ sample. The open squares represent the decay channels related to DAP recombinations in two f-SiC samples. All the related $A_{n}$ and $t_{n}$ were extracted from Fig. 3. The three curves represent the time-dependent non-equilibrium $h^{+}$densities corresponding to the overall negative $U$-centers, hexagonal site, and cubic site, where the time-resolved PL intensity $I(t) \propto \delta p(t)$.

different transition processes were also extracted from the carrier dynamics simulations and are summarized in Fig. 5. The overall, hexagonal- and cubic-site-related non-equilibrium $h^{+}$ lifetimes were calculated by Eq. (4), where the simulated $\tau_{p, 1}(t)$ and $\tau_{p, 2}(t)$ were found to be nearly time-independent and quite close to the corresponding time constants extracted from the TRPL fittings. Additionally, the above-mentioned two-stage distinction within the defect-related TRPL decay can be further confirmed considering the evolution of every $\tau_{p}(t)$ shown in Fig. 5. It can be seen that the evolution of $\tau_{p}(t)$ was influenced by both $E_{1}$ and $E_{2}$ related carrier dynamics at the early stage, while later it reached a longer lifetime between $\tau_{p, 1}(t)$ and $\tau_{p, 2}(t)$ and almost became time-independent.

\section{Influence of negative- $\boldsymbol{U}$ centers on PL properties}

In order to distinguish the contributions from the holeinvolved charge state transitions $E_{i}^{-} \rightarrow E_{i}^{0}$ and $E_{i}^{0} \rightarrow E_{i}^{+}$, we
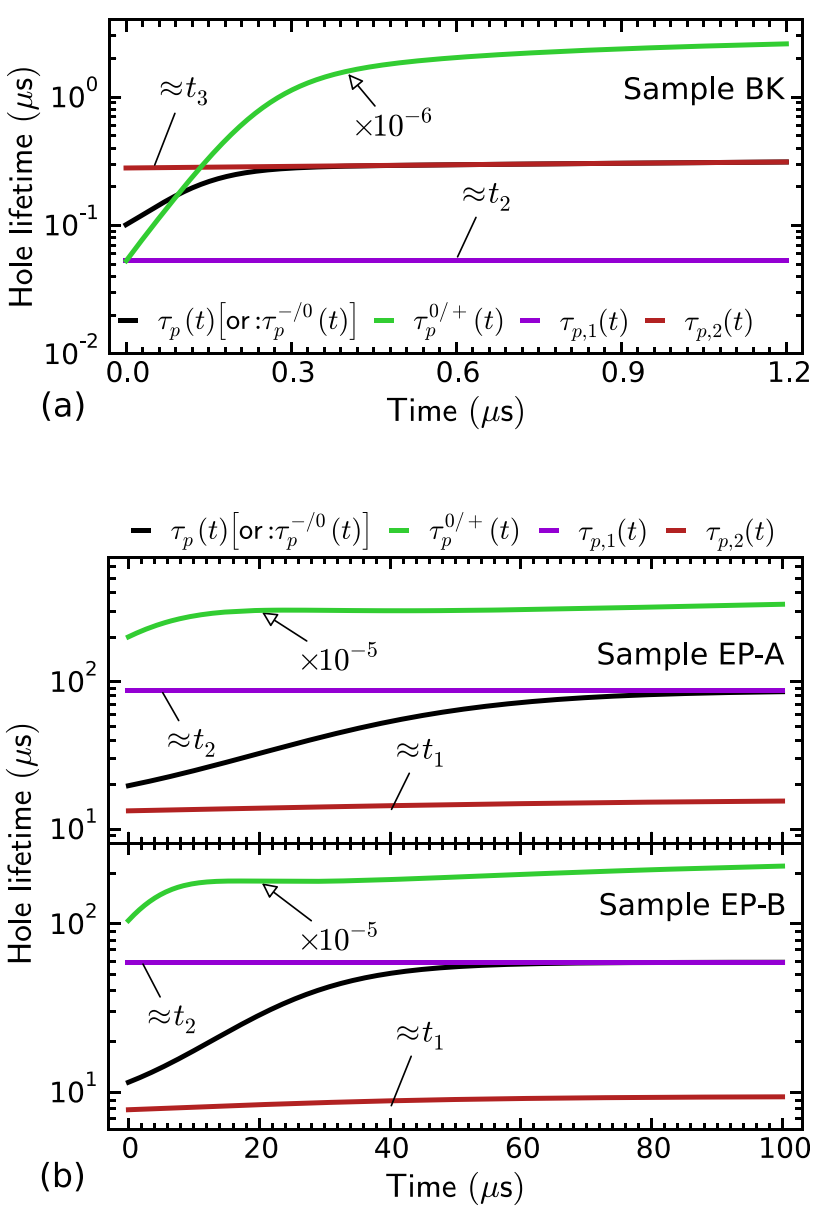

FIG. 5. Results of the negative $U$-center related carrier dynamics simulation for (a) sample BK and (b) samples EP-A and EP-B. Non-equilibrium $h^{+}$lifetimes of the entirety $\left(\tau_{p}(t)\right)$, the cubic- or hexagonal-site-related channel $\left(\tau_{p, 1}(t)\right.$ or $\left.\tau_{p, 2}(t)\right)$, and the $E_{i}^{-} \rightarrow E_{i}^{0}$ or $E_{i}^{0} \rightarrow E_{i}^{+}$transition $\left(\tau_{p}^{-/ 0}(t), \tau_{p}^{0 /+}(t)\right.$, respectively) related channel are presented.

introduced the "relative" $h^{+}$lifetimes for either transition where $\tau_{p}^{Q}=\left[\sum_{i}\left|R_{i, h}^{Q}\right| / \delta p(t)\right]^{-1}$ with $Q$ referring to “- $/ 0$ " or " $0 /+$." The simulated $\tau_{p}^{-/ 0}(t)$ and $\tau_{p}^{0 /+}(t)$ for each sample are also included in Fig. 5. It was found that $\tau_{p}^{0 /+}(t)$ for each sample was extremely long and has to be divided by $10^{6}$ (for bulk $\mathrm{SiC}$ ) or $10^{5}$ (for $\mathrm{f}-\mathrm{SiC}$ ) in order to be presented with other carrier lifetimes in Fig. 5. Instead, $\tau_{p}^{-/ 0}(t)$ was found to be nearly identical to $\tau_{p}(t)$ for each sample, which means that the $E_{i}^{-} \rightarrow E_{i}^{0}$ transitions dominate the hole capture process. Since all three samples in this work are heavily doped $n$-type, the Fermi level of each sample is close to the conduction band minimum. In this case, for a negative- $U$ system, the neutral carbon vacancy $\left(E_{i}^{0}\right)$ is favored at thermodynamic equilibrium. ${ }^{25}$ Hence, most of the $E_{i}^{0}$ states of the negative- $U$ centers were not likely to transfer further to the $E_{i}^{+}$states, causing the transition rate of $E_{i}^{0} \rightarrow E_{i}^{+}$to be extremely low.

It has been widely accepted that the $E_{1} / E_{2}$ centers are the carrier lifetime killers ${ }^{60}$ and contribute to the non-radiative recombinations. This agreed with our observation that the absolute PL intensity shown in Fig. 6 for each sample was inversely correlated with the estimated density of the $E_{1} / E_{2}$ center $\left(N_{u}\right)$ extracted from the respective TRPL measurement. The PL intensity of either EP-A or EP-B was $\sim 60$ or $\sim 40$ times higher than that of the bulk sample, respectively, and the 


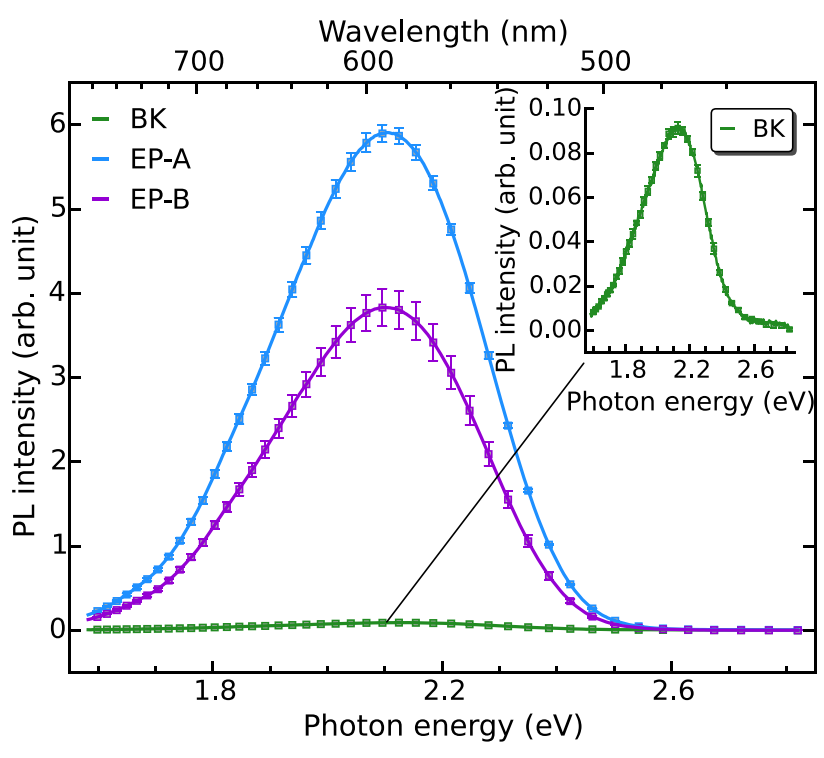

FIG. 6. Time-integrated PL intensity spectra of all three samples. Each error bar indicates the standard deviation (SD) at a certain wavelength, whereas each solid curve indicates the mean PL intensity. The inset is the zoom-in of the PL spectrum of sample BK.

$N_{u}$ of either f-SiC sample was two orders of magnitude lower than latter's as shown in Table I. Here, we implemented a simple equation slightly modified from the original form ${ }^{1}$ to evaluate the IQE (labelled as $\eta_{\text {int }}$ ) of our samples, where originally $\eta_{\text {int }}=1 /\left(1+\tau_{A} / \tau_{\text {nr }}\right)$ and $\tau_{A} \mid \tau_{\text {nr }}$ designate the $h^{+}$relaxation time $\mid$ the overall non-radiative lifetime separately. As we know $\tau_{\text {dap }} \approx \tau_{p}$ which was already mentioned in Sec. III B, $\tau_{p}$ actually represents the hole relaxation time equivalent to $\tau_{A}$. Hence, in our case, $\eta_{\text {int }}=1 /\left(1+\tau_{\text {dap }} / \tau_{\text {nr }}\right)$. For two f-SiC samples, by applying $\tau_{\text {dap }}=t_{3}$ and $1 / \tau_{\mathrm{nr}}=1 / t_{1}+1 / t_{2}$, the estimated IQE for samples EP-A and EP-B was found to be around $1.7 \%$ and $1.4 \%$, respectively. For sample BK, since the fourth decay channel with the longest time constant cannot be attributed to DAP recombination (see Sec. IV A for the related discussion), estimation of its IQE is unavailable; nonetheless, a rather low value of IQE compared to $\mathrm{f}-\mathrm{SiC}$ samples can be expected. To summarize how the $E_{1} / E_{2}$ defects could affect the IQE of our samples, we can see from Fig. 3 that higher $E_{1} /$ $E_{2}$ densities enlarge the difference between the $E_{1} / E_{2}$ related and DAP related injection levels and cause $\tau_{\mathrm{nr}}$ to be shorter. On the contrary, less non-equilibrium carriers are occupied by DAP related pathways, leading to lower intensity of DAP related luminescence. The trends on the pathways of both $E_{1} /$ $E_{2}$ and DAP would eventually result in lower IQE.

\section{Comparison between EP-A and EP-B}

Typically, the DAP recombination decay is described in the form of $t^{-m}$ rather than a single exponential decay process, where $t$ and $m$ designate the time and the power factor of decay, respectively. ${ }^{61}$ The above-mentioned methodology is suitable for modelling the DAP-related PL decay under high excitation power, where the effective DAP separation distance could change dramatically during the transient measurement period. However, our TRPL measurements were launched at a low injection level $\left(g \ll n_{0}\right)$ where the initial
DAP separation distance was already quite long compared with the average Bohr radius $\left(\sum_{j} a_{0}^{j} / 3\right)$ of the donors; therefore, the steady-state DAP recombination model was applied here to explain the DAP recombination process. The simulation results of the steady-state DAP recombination of the two f-SiC samples are summarized in Fig. 7 where the injection level allocated for either sample was set to $A_{3} g$ extracted from the fitting results in Fig. 3. The average DAP separation distances were calculated to be 3.79 times (EP-A) and 3.54 times (EP-B) the average Bohr radius of donors. It was believed that the shorter $r_{\text {dap }}$ of EP-B, which means denser DAP, was caused by its higher dopant concentration. The contrast between these two average $r_{\text {dap }}$ agreed well with the recognized trend of DAP lifetime, where the longer DAP separation distance could result in the lower DAP transition probability [see Eq. (B5)] and meanwhile cause longer DAP recombination lifetime. ${ }^{61,62}$

It was found that a higher portion of injection level was allocated to EP-A (17.7\%) than that of EP-B (12.9\%) as shown in Fig. 3, which caused the former's integrated PL intensity approximately 50\% higher than the latter's (see Fig. 6). On the contrary, from Fig. 3, we can see that a $4.8 \%$ more portion of non-equilibrium carriers, which was almost $40 \%$ of the amount for EP-B's DAP channel, were enrolled in the negative- $U$ center related carrier pathways in EP-B. Apparently, this was caused by the higher density of $E_{1} / E_{2}$ in EP-B than in EP-A as shown in Table I. As a result, we can see that EP-B had higher DAP transition probability (i.e., shorter average $r_{\text {dap }}$ ) but lower IQE than EP-A as mentioned in Sec. IV C. We believed that the higher $E_{1} / E_{2}$ defect density in sample EP-B came along with the higher nitrogen dopant compared with sample EP-A ${ }^{63}$ if the $\mathrm{C} / \mathrm{Si}$ ratio was

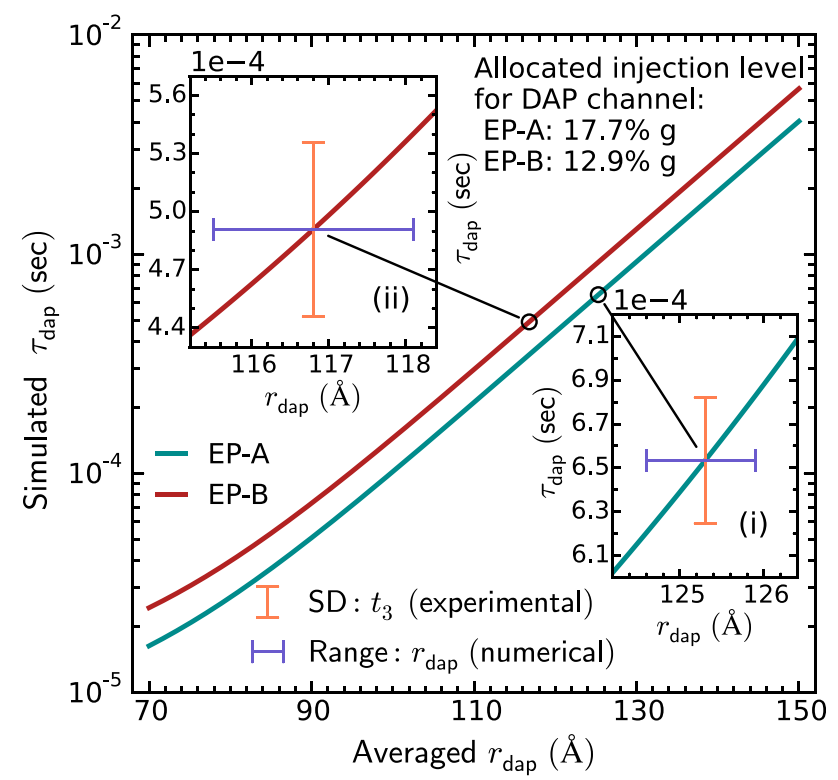

FIG. 7. Results of the pair-separation-dependent $\left(r_{\text {dap }}\right)$ DAP lifetime simulation of samples EP-A and EP-B. In the main graph, the values on the $y$-axis of the circled points are derived from $t_{3}$ of each $\mathrm{f}-\mathrm{SiC}$ sample in Fig. 3, whereas the corresponding values on the $x$-axis indicate the calculated $r_{\text {dap. }}$. In each inset, the error bar along the $y$-axis indicates the standard deviation of the fitted DAP lifetime, whereas the error bar along the $x$-axis indicates the corresponding range of the calculated DAP separation $\left(r_{\text {dap }}\right)$. 
controlled within a proper range. Otherwise, too low $\mathrm{C} / \mathrm{Si}$ ratio could facilitate the formation of $3 \mathrm{C} \mathrm{SiC}^{64}$ while too high $\mathrm{C} / \mathrm{Si}$ ratio could induce the high graphitization of the source. ${ }^{33}$ In addition, it was found that $\mathrm{C} / \mathrm{Si}$ ratio itself could also affect the density of negative- $U$ centers, e.g., the density of the $Z_{1} / Z_{2}$ centers in the $4 \mathrm{H} \mathrm{SiC}$ epilayer was found to decrease monotonically in the range of $\mathrm{C} / \mathrm{Si}$ ratio of 0.5-2.0. ${ }^{65}$ On the other hand, the formation of the $E_{1} / E_{2}$ related carbon vacancies could degrade the doping efficiency, ${ }^{66,67}$ where the large proportion of the donor impurities in $\mathrm{SiC}$ samples might be compensated. ${ }^{68,69}$ To summarize, reducing the formation of the $E_{1} / E_{2}$ defects in $\mathrm{f}$ $\mathrm{SiC}$ needs to be taken into consideration to find the new trade-off when optimizing the $\mathrm{C} / \mathrm{Si}$ ratio during the epilayer growth. Furthermore, despite the fact that the concentration of the nitrogen dopant in $\mathrm{f}-\mathrm{SiC}$ should be kept high enough $\left(>10^{18} \mathrm{~cm}^{-3}\right)$ to ensure the large density of DAP recombination, ${ }^{1}$ the nitrogen doping still requires further study to narrow down its range.

\section{CONCLUSIONS}

We have characterized two f-SiC samples with identical epilayer thicknesses and one bulk $6 \mathrm{H} \mathrm{SiC}$ substrate by applying TRPL and static PL measurements in which all the samples are heavily nitrogen-boron co-doped and n-type. An apparent trend was found that slower TRPL decay was accompanied by higher measured PL intensity. Negative- $U$ center $\left(E_{1} / E_{2}\right.$ defect) related carrier dynamics modelling and steady-state DAP recombination simulation were applied to the TRPL. The results of the carrier dynamics modelling revealed that the density of the $E_{1} / E_{2}$ defects in bulk $6 \mathrm{H} \mathrm{SiC}$ was found to be two orders of magnitude higher than that of either f-SiC epilayer. In addition, the ultrafast decay channel with the time constant of $\sim 3$ ns was extracted from the TRPL curve of the bulk substrate. This fast decay might be due to the joint effect from both Auger recombination and bimolecular recombination where both of the processes are considered as non-radiative. It is believed that the extra non-radiative decay channel and the much higher $E_{1} / E_{2}$ concentration in the bulk substrate caused quite lower PL intensity and IQE than those in the two f-SiC samples. The results of the steady-state DAP simulations on the f-SiC samples indicate that both the calculated average DAP separation distances $\left(r_{\text {dap }}\right)$ were three times larger than the average Bohr radius of an electron (captured by a neutral donor) at the low injection level (order: $\times 10^{11} \mathrm{~cm}^{-3}$ ). The longer $r_{\text {dap }}$ was found to result in a longer DAP recombination lifetime. Sample EP-B with a slightly higher density of $E_{1} / E_{2}$ defects was found to show more rapid TRPL decay and weaker static PL intensity along with lower IQE than sample EP-A. We believe that the C/Si ratio and the nitrogen doping level during the f-SiC epilayer growth still require further optimization to find the new trade-off between less $E_{1} / E_{2}$ defects and other indicators of the crystal quality, e.g., the extent of the graphitization of the source.

\section{ACKNOWLEDGMENTS}

The authors would like to thank Assoc. Professor Mikael Syväjärvi and Dr. Valdas Jokubavicius from IFM,
Linköping University for growing $6 \mathrm{H} \mathrm{f-SiC} \mathrm{samples} \mathrm{for} \mathrm{this}$ research. The authors also thank Dr. Peter David Girouard (Technical University of Denmark, Denmark) for the support on manuscript revision. Y.W. acknowledges the following researchers for fruitful discussions: Professor Dr.-Ing. Peter Wellmann (University of Erlangen-Nürnberg, Germany); Docent (Associate Professor) Dr. Jianwu Sun (Linköping University, Sweden); and Dr. Yiyu Ou (Technical University of Denmark, Denmark). This study was supported by Innovation Fund Denmark (No. 4106-00018B).

\section{APPENDIX A: NEGATIVE-U CENTER RELATED CARRIER DYNAMICS-GENERAL CONDITIONS}

As shown in Fig. 1, each dashed arrow originates from the provider (conduction band/ $D$-center) of the nonequilibrium carriers towards the corresponding charge state transition, where the related carrier capture rate was expressed in Eq. (A1) which was rewritten from Eq. (9) in Ref. 34

$$
\begin{aligned}
& R_{i, e}^{0 /-}(t)=\sigma_{i, e}^{0 /-}\left\langle\nu_{t h, e}\right\rangle\left\{\left[n_{0}+\delta n_{i}(t)\right] N_{i}^{0}(t)-n_{i}^{0 /-} N_{i}^{-}(t)\right\}, \\
& R_{i, e}^{+/ 0}(t)=\sigma_{i, e}^{+/ 0}\left\langle\nu_{t h, e}\right\rangle\left\{\left[n_{0}+\delta n_{i}(t)\right] N_{i}^{+}(t)-n_{i}^{+/ 0} N_{i}^{0}(t)\right\}, \\
& R_{i, h}^{-/ 0}(t)=\sigma_{i, h}^{-/ 0}\left\langle\nu_{t h, h}\right\rangle\left\{\left[p_{0}+\delta p_{i}(t)\right] N_{i}^{-}(t)-p_{i}^{-/ 0} N_{i}^{0}(t)\right\}, \\
& R_{i, h}^{0 /+}(t)=\sigma_{i, h}^{0 /+}\left\langle\nu_{t h, h}\right\rangle\left\{\left[p_{0}+\delta p_{i}(t)\right] N_{i}^{0}(t)-p_{i}^{0 /+} N_{i}^{+}(t)\right\} .
\end{aligned}
$$

The equilibrium $e^{-}, h^{+}$concentration was symbolized by $n_{0}, p_{0}$. The mean thermal velocity of $e^{-}$or $h^{-}$was represented by $\left\langle\nu_{t h, e(h)}\right\rangle=\left(3 k_{b} T / m_{e(h)}^{*}\right)^{0.5}$. The non-equilibrium $e^{-}, h^{+}$density as a function of time $(t)$ was designated as $\delta n_{i}(t), \delta p_{i}(t)$, where the subscript " $i$ " $(i \Rightarrow 1,2 L, 2 H)$ denotes the component of the negative- $U$ system: $E_{1}, E_{2 L}$, or $E_{2 H}$. The total non-equilibrium carrier density $\left(e^{-}\right.$or $\left.h^{+}\right)$at the certain time $t$ can be expressed by $\delta n(t), \delta p(t)$ $=\sum_{i} \delta n_{i}(t), \sum_{i} \delta p_{i}(t)$. The expressions of $n_{i}^{0 /-}, n_{i}^{+/ 0}$ are given by $^{70} n_{i}^{0 /-}, n_{i}^{+/ 0}=N_{c} \exp \left[-\Delta E_{i}^{L} /\left(k_{b} T\right)\right]$ (L: $0 /-$ or $+/ 0$ ), where $N_{c}$ is the effective density of states in the conduction band $\left(\mathrm{cm}^{-3}\right)$, while the expressions of $p_{i}^{-/ 0}, p_{i}^{0 /+}$ can be roughly estimated by $N_{a} \exp \left[-\left(E_{g}-\Delta E_{i}^{L}-\Delta E_{D}\right) /\left(k_{b} T\right)\right]$ (L: $-/ 0$ or $0 /+$ ).

The time-varying density of negative- $U$ center $\mathrm{i}$ with a charge state of $\mathrm{C}$ is designated as $N_{i}^{C}(t)(\mathrm{C}:-, 0,+)$, where the total density of the negative- $U$ center $^{34}$ at time $t$ is $N_{u}=\sum_{i} \sum_{C} N_{i}^{C}(t)$. Similarly, the net change of the charge state $E_{i}^{C}$ variation of one negative $U$ center should be equal to zero ${ }^{34}$ at any time $t$

$$
\sum_{C} \delta N_{i}^{C}(t)=0,
$$

where $\delta N_{i}^{C}(t)=N_{i}^{C}(t)-N_{i 0}^{C}$ represents the time-dependent density change of the charge state " $C$," and $N_{i 0}^{C}$ designates 
the initial density of the charge state " $C$." Note that at RT, all three centers are in the $E_{i}^{-}$state, which means $N_{i 0}^{+}, N_{i 0}^{0}$ $=0$ and $N_{i 0}^{-}=N_{u, i}$. By reconsidering the charge state transfer via $e^{-}$capture $^{20} E_{i}^{-} \rightarrow E_{i}^{0}+e^{-} \rightarrow E_{i}^{+}+2 e^{-}$, the net density of non-equilibrium $e^{-}$(majority carriers) is given by

$$
\delta n_{i}(t)-\delta p_{i}(t)=\delta N_{i}^{0}(t)+2 \delta N_{i}^{+}(t) .
$$

\section{APPENDIX B: STEADY-STATE DAP RECOMBINATION CALCULATION-GENERAL CONDITIONS}

As shown in Fig. 2, the dashed $\mid$ solid pathways indicate the dominating DAP recombination channel for $n$-type $\mid p$ type $6 \mathrm{H} \mathrm{SiC}$, where the carrier capture/emission would reach equilibrium in the steady-state. Therefore, based on Eq. (5), we can summarize the condition for the steady-state DAP recombination as shown in Eq. (B1). Note that $N_{\text {eff }}^{j}$ designates the effective $e^{-}-h^{+}$pair concentration related to each donor site for DAP recombination in which $N_{\text {eff }}^{j}$ is dependent on the density of $e^{-}$at each donor state $E_{j}{ }^{9}$ Here, we derived $N_{\text {eff }}^{j}$ from the allocated injection level for DAP recombination $g_{\text {dap }}$ and the static Fermi level $E_{F}$ using Eq. (B2). It is worthwhile mentioning that at such a low injection level $\left(\sim \times 10^{11} \mathrm{~cm}^{-3}\right)$, the quasi-Fermi level for $e^{-}$is almost identical to the static Fermi level $E_{F}$. The calculation of $E_{F}$ was derived from Ref. 36

$$
\begin{gathered}
p_{0} N_{1}^{j} C_{p 1}-N_{0}^{j} e_{p 0}=R_{0 \rightarrow 1^{\prime}}^{j}, \\
p_{0} N_{2}^{j} C_{p 2}-N_{1^{\prime}}^{j} e_{p 1^{\prime}}=R_{2 \rightarrow 1^{\prime}}^{j}, \\
t_{j^{\prime}}^{\prime} N_{1^{\prime}}^{j}-t_{j} N_{1}^{j}=R_{0 \rightarrow 1^{\prime}}^{j}+R_{2 \rightarrow 1^{\prime}}^{j}, \\
N_{1^{\prime}}^{j} e_{n 1^{\prime}}^{j}+p_{0} N_{1}^{j} C_{p 1}-\left(e_{p 0}+n_{0} C_{n 0}^{j}\right) N_{0}^{j}=0, \\
N_{1^{\prime}}^{j} e_{p 1^{\prime}}+n_{0} N_{1}^{j} C_{n 1}^{j}-\left(e_{n 2}^{j}+p_{0} C_{p 2}\right) N_{2}^{j}=0, \\
\sum_{S} N_{S}^{j}=N_{\mathrm{eff}}^{j}, \\
N_{\mathrm{eff}}^{j}=\frac{g_{\text {dap }}}{1+1 / g_{D} \exp \left(\left(E_{g}-\Delta E_{j}-E_{F}\right) /\left(k_{b} T\right)\right)} .
\end{gathered}
$$

Here, we introduced four auxiliary parameters shown in Eq. (B3) that represent the carrier densities at each perturbed/unperturbed donor/acceptor level by treating these levels as pseudo-Fermi levels temporarily. The emission probabilities in Eq. (B1) could be derived from the capture probabilities related to the reversed paths by applying the parameters obtained from Eq. (B3), where $e_{n 1^{\prime}}^{j}=n_{d, u} C_{n 0}^{j}$, $e_{n 2}^{j}=n_{d, p} C_{n 1}^{j}, e_{p 0}=p_{a, p} C_{p 1}$, and $e_{p 1^{\prime}}=p_{a, u} C_{p 2}$

$$
\begin{gathered}
n_{d, p}^{j}=n_{0} \exp \left(\frac{E_{g}-\Delta E_{j}-E_{F}}{k_{b} T}\right), \\
n_{d, u}^{j}=n_{0} \exp \left(\frac{E_{g}-\Delta E_{j}+U_{E}\left(r_{\text {dap }}\right)-E_{F}}{k_{b} T}\right), \\
p_{a, p}=p_{0} \exp \left(\frac{E_{F}-\Delta E_{D}}{k_{b} T}\right),
\end{gathered}
$$

$$
p_{a, u}=p_{0} \exp \left(\frac{E_{F}-\Delta E_{D}-U_{E}\left(r_{\mathrm{dap}}\right)}{k_{b} T}\right) .
$$

Since the relation between $t_{j}$ and $t_{j}^{\prime}$ follows Eq. (B4), it can be deduced that $t_{j}^{\prime} \gg t_{j}$ at RT. Now, $t_{j}^{\prime}$ can be treated as the net DAP transition probability where it is preferable to relabel $t_{j}^{\prime}$ into the more general form, namely, $W\left(r_{\text {dap }}\right)$. Here, we adopted the expression of $W\left(r_{\text {dap }}\right)$ from Ref. 71 shown in Eq. (B5), which is suitable for the DAP transitions with strong phonon replicas. Hagen et al. (Ref. 62) experimentally found that $W_{0}$ of $6 \mathrm{H} \mathrm{SiC}$ should be $(3-4) \times 10^{5} \mathrm{~s}^{-1}$. Here, we applied $W_{0}=3.5 \times 10^{5} \mathrm{~s}^{-1} . a_{0}^{j}$ denotes the Bohr radius related to different donor levels in $6 \mathrm{H} \mathrm{SiC} \mathrm{using} \mathrm{Eq.} \mathrm{(B6)}{ }^{43}$

$$
\begin{gathered}
\frac{t_{j}^{\prime}}{t_{j}}=\exp \left(\frac{\Delta E_{j}+\Delta E_{D}+U_{E}\left(r_{\mathrm{dap}}\right)}{k_{b} T}\right), \\
W_{j}\left(r_{\mathrm{dap}}\right)=W_{0} \exp \left(-\frac{2 r_{\mathrm{dap}}}{a_{0}^{j}}\right) \\
a_{0}^{j}=\left(\frac{e h^{2}}{8 \pi^{2} m_{e}^{*}\left(\varepsilon_{0} \varepsilon_{r}\right)^{2}} \frac{1}{\Delta E_{j}^{3}}\right)^{1 / 4}
\end{gathered}
$$

\section{APPENDIX C: SIMULATION OF $\tau_{\text {dap }}$ OF SAMPLE BK WITH DIFFERENT INJECTION LEVELS $g$}

The simulation results of $\tau_{\text {dap }}$ of sample BK are summarized in Fig. 8, where $1 \%, 5 \%$, and $10 \%$ to $100 \%$ (with $10 \%$

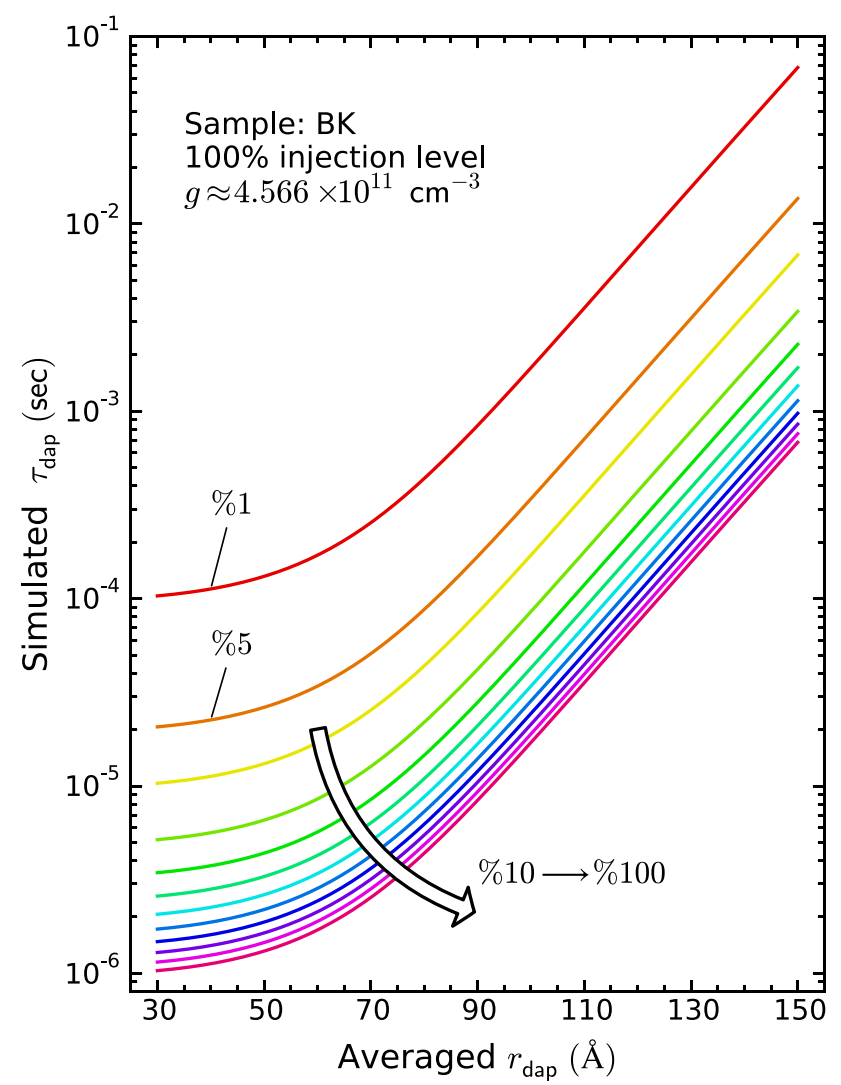

FIG. 8. Simulated $\tau_{\text {dap }}$ of sample BK. The proportion of the non-equilibrium carriers for DAP recombination varies from $1 \%$ to $100 \%$ of the injection level. 
interval) of the injection level $g$ were allocated to the channel of the DAP recombination in each simulation. The results suggest that $\tau_{\text {dap }}$ decreases with increasing injection level $g$. We can see that the calculated $\tau_{\text {dap }}$ was longer than $20 \mu \mathrm{s}$ assuming that $5 \%$ of $g$ was allocated to the DAP recombination channel. Therefore, one can expect that the related $\tau_{\text {dap }}$ should be even longer than $20 \mu \mathrm{s}$ if the fourth recombination channel in sample BK (with $A_{4}=1.2 \%$, see Fig. 3) was treated as the DAP recombination channel. Considering the fact that the fourth recombination channel in sample BK has a lifetime of $4.801 \mu$ s (see Fig. 3), it is not related to the DAP recombination channel.

${ }^{1}$ S. Kamiyama, T. Maeda, Y. Nakamura, M. Iwaya, H. Amano, I. Akasaki, H. Kinoshita, T. Furusho, M. Yoshimoto, T. Kimoto, J. Suda, A. Henry, I. G. Ivanov, J. P. Bergman, B. Monemar, T. Onuma, and S. F. Chichibu, J. Appl. Phys. 99, 093108 (2006).

${ }^{2}$ S. Kamiyama, M. Iwaya, T. Takeuchi, I. Akasaki, R. Yakimova, and M. Syväjärvi, Thin Solid Films 522, 23 (2012).

${ }^{3}$ H. Ou, Y. Ou, A. Argyraki, S. Schimmel, M. Kaiser, P. Wellmann, M. K. Linnarsson, V. Jokubavicius, J. Sun, R. Liljedahl, and M. Syväjärvi, Eur. Phys. J. B 87, 58 (2014).

${ }^{4}$ S. Kamiyama, M. Iwaya, T. Takeuchi, I. Akasaki, M. Syväjärvi, and R. Yakimova, J. Semicond. 32, 013004 (2011).

${ }^{5}$ M. Syväjärvi, J. Müller, J. Sun, V. Grivickas, Y. Ou, V. Jokubavicius, P. Hens, M. Kaisr, K. Ariyawong, K. Gulbinas, P. Hens, R. Liljedahl, M. K. Linnarsson, S. Kamiyama, P. Wellmann, E. Spiecker, and H. Ou, Phys. Scr. T148, 014002 (2012).

${ }^{6}$ Y. Ou, V. Jokubavicius, R. Yakimova, M. Syväjärvi, and H. Ou, Opt. Lett. 37, 3816 (2012).

${ }^{7}$ Y. Ou, X. Zhu, V. Jokubavicius, R. Yakimova, N. A. Mortensen, M. Syväjärvi, S. Xiao, and H. Ou, Sci. Rep. 4, 4662 (2014).

${ }^{8}$ W. Lu, Y. Ou, E. M. Fiordaliso, Y. Iwasa, V. Jokubavicius, M. Syväjärvi, S. Kamiyama, P. M. Petersen, and H. Ou, Sci. Rep. 7, 9798 (2017).

${ }^{9}$ Y. Ou, V. Jokubavicius, S. Kamiyama, C. Liu, R. W. Berg, M. Linnarsson, R. Yakimova, M. Syväjärvi, and H. Ou, Opt. Mater. Express 1, 1439 (2011).

${ }^{10}$ J. W. Sun, V. Jokubavicius, R. Liljedahl, R. Yakimova, S. Juillaguet, J. Camassel, S. Kamiyama, and M. Syväjärvi, Thin Solid Films 522, 33 (2012).

${ }^{11}$ G. Manolis, K. Gulbinas, V. Grivickas, V. Jokubavicius, M. K. Linnarsson, and M. Syväjärvi, IOP Conf. Ser.: Mater. Sci. Eng. 56, 012006 (2014)

${ }^{12}$ S. Schimmel, M. Kaiser, V. Jokubavicius, Y. Ou, P. Hens, M. K. Linnarsson, J. Sun, R. Liljedahl, H. Ou, M. Syväjärvi, and P. Wellmann, IOP Conf. Ser.: Mater. Sci. Eng. 56, 012002 (2014).

${ }^{13}$ M. Aboelfotoh and J. Doyle, Phys. Rev. B 59, 10823 (1999).

${ }^{14}$ T. Dalibor, G. Pensl, H. Matsunami, T. Kimoto, W. J. Choyke, A. Schöner, and N. Nordell, Phys. Status Solidi A 162, 199 (1997).

${ }^{15}$ S. Sasaki, K. Kawahara, G. Feng, G. Alfieri, and T. Kimoto, J. Appl. Phys. 109, 013705 (2011)

${ }^{16}$ M. Weidner, T. Frank, G. Pensl, A. Kawasuso, H. Itoh, and R. KrauseRehberg, Physica B 308-310, 633 (2001).

${ }^{17}$ G. Pensl, T. Frank, M. Krieger, M. Laube, S. Reshanov, F. Schmid, and M. Weidner, Physica B 340-342, 121 (2003).

${ }^{18}$ X. D. Chen, C. L. Yang, M. Gong, W. K. Ge, S. Fung, C. D. Beling, J. N. Wang, M. K. Lui, and C. C. Ling, Phys. Rev. Lett. 92, 125504 (2004).

${ }^{19}$ C. Hemmingsson, N. T. Son, O. Kordina, E. Janzén, and J. L. Lindström, J. Appl. Phys. 84, 704 (1998)

${ }^{20}$ C. G. Hemmingsson, N. T. Son, and E. Janzén, Appl. Phys. Lett. 74, 839 (1999).

${ }^{21}$ G. D. Watkins and J. R. Troxell, Phys. Rev. Lett. 44, 593 (1980).

${ }^{22}$ G. A. Baraff, E. O. Kane, and M. Schlüter, Phys. Rev. Lett. 43, 956 (1979).

${ }^{23}$ P. W. Anderson, Phys. Rev. Lett. 34, 953 (1975).

${ }^{24}$ F. Bechstedt, A. Zywietz, and J. Furthmüller, Europhys. Lett. 44, 309 (1998).

${ }^{25}$ A. Zywietz, J. Furthmüller, and F. Bechstedt, Phys. Rev. B 59, 15166 (1999).

${ }^{26}$ M. Gong, S. Fung, C. D. Beling, and Z. You, J. Appl. Phys. 85, 7604 (1999).
${ }^{27}$ A. A. Lebedev, A. I. Veinger, and D. V. Davydov, J. Appl. Phys. 88, 6265 (2000).

${ }^{28}$ A. Kurtz, E. Muñoz, J. M. Chauveau, and A. Hierro, J. Phys. D 50, 065104 (2017).

${ }^{29} \mathrm{M}$. Lades, "Modeling and simulation of wide bandgap semiconductor devices: 4H/6H-SiC," Ph.D. thesis (Technische Universität München, 2000).

${ }^{30}$ J. P. Bergman, O. Kordina, and E. Janzén, Phys. Status Solidi A 162, 65 (1997).

${ }^{31}$ J. P. Bergman, Diamond Relat. Mater. 6, 1324 (1997).

${ }^{32} \mathrm{M}$. Syväjärvi and R. Yakimova, in Comprehensive Semiconductor Science and Technology, edited by P. Bhattacharya, R. Fornari, and H. Kamimura (Elsevier, Amsterdam, 2011), pp. 202-231.

${ }^{33}$ V. Jokubavicius, P. Hens, R. Liljedahl, J. W. Sun, M. Kaiser, P. Wellmann, S. Sano, R. Yakimova, S. Kamiyama, and M. Syväjärvi, Thin Solid Films 522, 7 (2012).

${ }^{34}$ P. B. Klein, J. Appl. Phys. 103, 033702 (2008).

${ }^{35}$ S. Sridhara, T. Eperjesi, R. Devaty, and W. Choyke, Mater. Sci. Eng. B 61-62, 229 (1999).

${ }^{36} \mathrm{~V}$. Zeghbroeck, Principles of Semiconductor Devices and Heterojunctions (Prentice Hall PTR, 2007).

${ }^{37}$ E. Janzén, A. Gali, A. Henry, I. G. Ivanov, B. Magnusson, and N. T. Son, in Defects in Microelectronic Materials and Devices, edited by D. Fleetwood and R. Schrimpf (Taylor \& Francis, 2008), pp. 615-670.

${ }^{38}$ L. W. Aukerman and M. F. Millea, Phys. Rev. 148, 759 (1966).

${ }^{39}$ W. Suttrop, G. Pensl, and P. Lanig, Appl. Phys. A 51, 231 (1990).

${ }^{40}$ W. Lambrecht, S. Limpijumnong, S. Rashkeev, and B. Segall, Phys. Status Solidi B 202, 5 (1997).

${ }^{41}$ W. Suttrop, G. Pensl, W. J. Choyke, R. Stein, and S. Leibenzeder, J. Appl. Phys. 72, 3708 (1992).

${ }^{42}$ A. Koizumi, V. P. Markevich, N. Iwamoto, S. Sasaki, T. Ohshima, K. Kojima, T. Kimoto, K. Uchida, S. Nozaki, B. Hamilton, and A. R. Peaker, Appl. Phys. Lett. 102, 032104 (2013).

${ }^{43}$ M. Lax, Phys. Rev. 119, 1502 (1960).

${ }^{44}$ V. Abakumov, V. Perel, and I. Yassievich, Sov. Phys. Semicond. 12, 1 (1978)

${ }^{45}$ P. B. Klein, B. V. Shanabrook, S. W. Huh, A. Y. Polyakov, M. Skowronski, J. J. Sumakeris, and M. J. O'Loughlin, Appl. Phys. Lett. 88, 052110 (2006).

${ }^{46}$ Here we have implemented different values of $k$ for $\sigma_{i, h}=k \times \sigma_{i, e}^{+/ 0}$. in the negative- $U$ centers related carrier dynamics simulations where $k \in[5,10]$. It was found that the variation of $k$ within such a range does not affect the simulated TRPL decay curve.

${ }^{47}$ L. F. Shampine and M. W. Reichelt, SIAM J. Sci. Comput. 18, 1 (1997).

${ }^{48}$ W. Shockley and J. T. Last, Phys. Rev. 107, 392 (1957).

${ }^{49}$ A. A. Lebedev, Semiconductors 33, 107 (1999).

${ }^{50}$ K. Neimontas, T. Malinauskas, R. Aleksiejūnas, M. Sūdžius, K. Jarašiūnas, L. Storasta, J. P. Bergman, and E. Janzen, Semicond. Sci. Technol. 21, 952 (2006)

${ }^{51}$ N. Ramungul, V. Khemka, T. Chow, M. Ghezzo, and J. W. Kretchmer, Mater. Sci. Forum 264-268, 1065 (1998).

${ }^{52}$ A. Galeckas, J. Linnros, V. Grivickas, U. Lindefelt, and C. Hallin, Appl. Phys. Lett. 71, 3269 (1997)

${ }^{53}$ A. B. Sproul, J. Appl. Phys. 76, 2851 (1994).

${ }^{54}$ A. Galeckas, J. Linnros, M. Frischholz, K. Rottner, N. Nordell, S. Karlsson, and V. Grivickas, Mater. Sci. Eng. B 61-62, 239 (1999).

${ }^{55}$ M. Ikeda, H. Matsunami, and T. Tanaka, Phys. Rev. B 22, 2842 (1980).

${ }^{56}$ K. Gulbinas, P. Ščajev, V. Bikbajavas, V. Grivickas, O. V. Korolik, A. V. Mazanik, A. K. Fedotov, V. Jokubavičius, M. K. Linnarsson, M. Syväjärvi, and S. Kamiyama, IOP Conf. Ser.: Mater. Sci. Eng. 56, 012005 (2014).

${ }^{57}$ P. Ščajev and K. Jarašiunas, J. Phys. D 46, 265304 (2013).

${ }^{58}$ V. Grivickas, K. Gulbinas, V. Jokubaviius, J. W. Sun, M. Karalinas, S. Kamiyama, M. Linnarsson, M. Kaiser, P. Wellmann, and M. Syväjärvi, IOP Conf. Ser.: Mater. Sci. Eng. 56, 012004 (2014).

${ }^{59}$ S. A. Reshanov, K. Schneider, R. Helbig, G. Pensl, H. Nagasawa, and A. Schöner, Mater. Sci. Forum 457-460, 513 (2004).

${ }^{60}$ K. Danno, D. Nakamura, and T. Kimoto, Appl. Phys. Lett. 90, 202109 (2007).

${ }^{61}$ A. Suzuki, H. Matsunam, and T. Tanaka, J. Phys. Chem. Solids 38, 693 (1977).

${ }^{62}$ S. Hagen, A. Van Kemenade, and J. Van Der Does De Bye, J. Lumin. 8, 18 (1973).

${ }^{63}$ I. Pintilie, L. Pintilie, K. Irmscher, and B. Thomas, Appl. Phys. Lett. 81, 4841 (2002)

${ }^{64}$ V. Jokubavicius, M. Kaiser, P. Hens, P. J. Wellmann, R. Liljedahl, R. Yakimova, and M. Syväjärvi, Mater. Sci. Forum 740-742, 19 (2013). 
${ }^{65}$ T. Kimoto, K. Hashimoto, and H. Matsunami, Jpn. J. Appl. Phys., Part 1 42, 7294 (2003).

${ }^{66}$ C. Wang, J. Bernholc, and R. F. Davis, Phys. Rev. B 38, 12752 (1988).

${ }^{67}$ H. Itoh, A. Kawasuso, T. Ohshima, M. Yoshikawa, I. Nashiyama, S Tanigawa, S. Misawa, H. Okumura, and S. Yoshida, Phys. Status Solidi A 162, 173 (1997).

${ }^{68}$ M. Yamanaka, H. Daimon, E. Sakuma, S. Misawa, and S. Yoshida, J. Appl. Phys. 61, 599 (1987).

${ }^{69}$ H. J. Kim and R. F. Davis, J. Electrochem. Soc. 133, 2350 (1986).
${ }^{70}$ W. Shockley and W. T. Read, Phys. Rev. 87, 835 (1952).

${ }^{71}$ D. G. Thomas, J. J. Hopfield, and W. M. Augustyniak, Phys. Rev. 140, A202 (1965).

${ }^{72}$ T. Kimoto and J. A. Cooper, Fundamentals of Silicon Carbide Technology (John Wiley \& Sons Singapore Pte. Ltd, 2014), pp. 11-38.

${ }^{73}$ G. Harris, Properties of Silicon Carbide, EMIS Data Reviews Series (INSPEC, the Institution of Electrical Engineers, 1995).

${ }^{74}$ C. Persson, U. Lindefelt, and B. E. Sernelius, J. Appl. Phys. 86, 4419 (1999).

${ }^{75}$ Y. Varshni, Physica 34, 149 (1967). 